\title{
A Teoria dos Campos Conceituais e o Ensino de Ciências: Uma Revisão
}

\section{The Theory of Conceptual Fields and Science Teaching: A Review}

\author{
Kariny Mery Araujo Cunha \\ Brasil \\ Luciana Nobre de Abreu Ferreira \\ Brasil
}

No presente manuscrito buscou-se conhecer as principais linhas de investigação do uso da Teoria dos Campos Conceituais (TCC) no ensino de ciências naturais (Química, Física e Biologia) exploradas em pesquisas de periódicos nacionais e internacionais e nas atas do Encontro Nacional de Pesquisas em Educação em Ciências (ENPEC). Para tanto, foi realizada uma revisão em periódicos da área de ensino de ciências no intervalo de 2008 a 2018 e nas atas de 2007 a 2017 do ENPEC. A partir da busca realizada foram localizados 66 trabalhos, entre estudos teóricos e empíricos, abordando a temática. A análise indicou as potencialidades da TCC na construção de conceitos pelos sujeitos em diferentes níveis de ensino e na evolução em campos conceituais, bem como no auxílio a professores na elaboração de procedimentos metodológicos que favorecem o ensino de conceitos científicos.

Palavras-chave: ensino de ciências; teoria dos campos conceituais; revisão bibliográfica.

This manuscript sought to examine the main lines of investigation on the use of the Theory of Conceptual Fields (TCF) in the teaching of natural sciences (Chemistry, Physics and Biology) explored in research studies in national and international journals and the minutes of the National Research Meeting in Science Education (ENPEC). For this, we carried out a review of journals on the field of science teaching from 2008 to 2018 and the ENPEC minutes from 2007 to 2017. Our search retrieved 66 works that addressed the subject, among theoretical and empirical studies. The analysis pointed out the potential of TCF for the construction of concepts by subjects at different levels of education and the evolution in conceptual fields, as well as for assisting teachers in the elaboration of methodological procedures that support the teaching of scientific concepts.

Keywords: science teaching; theory of conceptual fields; literature review. 


\section{Introdução}

Pesquisasvoltadasà compreensão de processos cognitivos relativos à aprendizagem configuram um conteúdo pedagógico de extrema relevância para a melhoria do ensino das ciências naturais (Scheffler, \& Del Pino, 2013). Nesse sentido, diferentes teorias, pertencentes ao domínio da didática, dão enfoque a isso por reconhecerem a relevância de "aprender como se aprende" (Bigge, 1977 citado em Vasconcelos, Praia, \& Almeida, 2003, p. 11), o que é essencial para ensinar de modo significativo. Como destaca Freire (1996), ensinar não consiste apenas em transmitir conhecimento, mas em oferecer oportunidade para a construção de conhecimento dos sujeitos, o que se favorece quando o professor conhece de que forma o aluno compreende determinado conteúdo (Vergnaud, Rogalski, \& Artique, 1989).

Dentre elas, cabe destacar a Teoria dos Campos Conceituais (TCC) de Gérard Vergnaud, de natureza cognitivista, neopiagetiana, a qual enfoca o estudo do desenvolvimento cognitivo e da aprendizagem de competências complexas dos estudantes, em função da resolução de situações atinentes ao conteúdo inserido em um "campo de conceitos" distintos entre si, porém correlacionados (Moreira, 2002; Vergnaud, 2009). Logo, nesta teoria propõe-se identificar e analisar as conexões existentes entre os conhecimentos à luz dos conteúdos conceituais, bem como os invariantes operatórios tácitos no desempenho dos sujeitos, buscando compreender as filiações e rupturas na formação do conhecimento (Vergnaud, 2017a).

Assim, o enfrentamento dos estudantes às diferentes situações (e mais complexas) favorece o seu desenvolvimento cognitivo e permite o domínio de múltiplos conceitos, isto é, promove o processo de conceitualização que se refere à interação entre as informações constantes nas situações e a estrutura cognitiva do indivíduo (Grings, Caballero, \& Moreira, 2006). Por essa razão, Moreira (2009) explica que o foco da teoria de Vergnaud está no estudo do funcionamento cognitivo do "sujeito-em-situação". Nesse sentido, a teoria apresenta característica pragmática, visto que presume que a obtenção de conhecimento é ajustada por situações-problema, bem como as ações do sujeito em situação, por meio das quais um conceito adquire sentido (Moreira, 2002). Vergnaud (1996) considera que a definição de "conhecimentos" está relacionada tanto ao saber fazer (resolução de problemas), quanto ao saber expressar, isto é, saber explicitar os objetos e suas propriedades.

Vergnaud (2017a) parte do princípio que o conhecimento organiza-se em campos conceituais, por isso atribui à definição de conceito outro significado, podendo ser entendido como um tríplice conjunto de elementos distintos, porém dependentes, os quais seriam: $S$ (conjunto de situações que tornam o conceito significativo), I (conjunto de invariantes operacionais que instituem o conceito e estruturam as formas de organização do pensamento, os quais serão evocados pelas situações) e L (conjunto de representações linguísticas e simbólicas usadas para retratar o conceito, suas propriedades e as situações ao qual estão relacionados).

A relação entre os componentes desse conjunto se estabelece na dependência dos 
invariantes para com as situações e esquemas utilizados pelo sujeito em situação, isto é, a apropriação de um conceito requer enfrentar uma situação (S), evocar os invariantes operatórios (I) e representá-los (L). Os invariantes podem ser divididos em duas classes: conceitos-em-ação (objeto, predicado ou categoria de pensamento, pertinente ou não) e teoremas-em-ação (proposição que se supõe verdadeira pelo indivíduo, a qual pode estar certa ou errada cientificamente). Por isso, os três devem ser estudados de modo simultâneo, uma vez que "um único conceito não se refere a um só tipo de situação e uma única situação não pode ser analisada com um só conceito" (Cedran, \& Kiouranis, 2019; Moreira, 2002).

Vergnaud $(2013,2017 b)$ coloca que a TCC busca investigar as dificuldades conceituais dos alunos elaborando meios para superá-las e complementa que é infrutífero "contornar as dificuldades conceituais", pois, é por meio da identificação e enfrentamento delas que podem ser superadas. Todavia, esse processo ocorre de modo gradual.

Além da compreensão de como ocorre a construção conceitual, Vergnaud (2017a, 2017b) defende que a TCC é capaz de subsidiar a ação do professor, uma vez que focaliza a forma operatória do conhecimento (o fazer) e a forma predicativa (o explicar, o dizer) o que, de acordo com Grings, Caballero e Moreira (2008), corrobora a relevância da proposição de situações que facultam a análise das competências do fazer e do dizer. Nesse sentido, Vergnaud (2017b) sugere que a ação mediadora do professor está pautada na escolha de situações; no acompanhamento dos alunos durante a resolução dessas situações e na avaliação de controle do desenvolvimento cognitivo de seus alunos. Assim, a TCC enseja ao professor auxílio didático-metodológico ao proporcionar a compreensão da aprendizagem e o delineamento de estratégias que visem ajudar os estudantes a progredirem conceitualmente (Moreira, 2002).

Isso posto, no presente manuscrito tomamos por objetivo conhecer as principais linhas de investigação do uso da TCC no ensino de ciências naturais apresentadas em pesquisas de periódicos nacionais e internacionais e nas atas do Encontro Nacional de Pesquisa no Ensino de Ciências (ENPEC). Para tanto, foi realizado um mapeamento da produção acadêmica referente à temática em periódicos da área, levando em consideração que pesquisas assim estruturadas configuram significativo subsídio a pesquisadores, ao possibilitarem uma visualização panorâmica das características e tendências a respeito da temática estudada.

\section{Procedimentos metodológicos}

Este trabalho é decorrente de uma revisão bibliográfica sistemática que, segundo Linde e Willich (2003), é útil para tornar os resultados e conclusões os mais objetivos possível. Por ser uma forma de pesquisa que utiliza dados da literatura a respeito de um tema, permite a análise de aspectos coincidentes e entrelinhas das pesquisas como base para estudos posteriores.

Nesta revisão investigamos as principais características dos artigos publicados no período de 2008 a 2018 em revistas nacionais e internacionais pertencentes à área 
de ensino (área 46, antiga área de Ensino de Ciências e Matemática) - classificação da Coordenação de Aperfeiçoamento de Pessoal de Nível Superior (CAPES). Além dos periódicos, foram consultadas também as atas do ENPEC, no intervalo de 2007 a 2017 , disponíveis na internet. Vale destacar que não foi incluído nesta investigação o último ENPEC, realizado em 2019, uma vez que no período de busca dos trabalhos as atas ainda não estavam disponíveis para consulta.

Para a seleção dos artigos tomamos como primeiro critério a avaliação dos periódicos pelo programa Qualis da CAPES (estratificação da qualidade da produção intelectual dos programas de pós-graduação) relativa ao quadriênio 2013-2016. Para tanto, consideramos as revistas classificadas com os conceitos A1, A2, B1 e B2 para a área de ensino. Com esse delineamento de busca, foram selecionados periódicos nacionais e internacionais, dentre os quais foram excluídos aqueles exclusivamente pertencentes à área de ensino de matemática. Dessa forma, um total de 58 revistas foi pesquisado, sendo 35 nacionais e 23 internacionais.

Para o desenvolvimento do método de busca, organização e identificação dos dados da pesquisa tomamos como suporte os parâmetros e métodos estabelecidos pela Análise de Conteúdo (AC) de Bardin (1977). Tendo em vista a seleção dos trabalhos, selecionamos aqueles que apresentam palavras relacionadas à temática, com termos (índices) presentes no título, parte do texto e/ou palavras-chave, tais como: “Teoria dos Campos Conceituais", "Theory of conceptuals fields", “Teoria de Campos Conceituais" (foram consideradas as duas formas escritas para a busca ao percebermos que havia trabalhos que abordavam o tema tanto usando a contração "do" como a preposição "de"), "Campos Conceituais" (nem todos os trabalhos usavam todo o termo "Teoria dos Campos Conceituais"), "Invariantes operatórios", "Vergnaud", "campo conce (além da forma de abordagem do tema no singular, também havia trabalhos escritos em espanhol, assim, a palavra de busca escrita dessa maneira facilitou a localização desses trabalhos). O asterisco serviu como caractere "coringa" para a busca, pois permitiu a localização de um grande número de palavras análogas, como por exemplo, ao se buscar por "conce ${ }^{\star " ~ f o i ~ p o s s i ́ v e l ~ e n c o n t r a r ~ d i v e r s a s ~ p a l a v r a s ~ q u e ~ c o m e c ̧ a s s e m ~ d e s s a ~ f o r m a, ~}$ tais como: conceito, conceituação, conceitualização, conceptos, conceptualização, conceptualization, entre outras.

O levantamento bibliográfico nas revistas foi realizado na ferramenta de busca disponível no website de cada uma delas, porém, nem todas as revistas escolhidas para a revisão possuíam tal ferramenta, por isso, a pesquisa foi realizada inicialmente com a leitura dos títulos dos artigos, número a número. Não obstante, optou-se posteriormente pela seleção manual de trabalhos que continham termos pertinentes à temática no título, com o auxílio do comando "ctrl+f”. Após a realização desses procedimentos, encontramos trabalhos relativos à temática em 16 dos 58 periódicos pesquisados, cuja lista encontrase apresentada na Tabela 1, com os respectivos conceitos Qualis e quantidade de artigos selecionados.

De modo semelhante foi feita a busca nas atas do ENPEC, ou seja, utilizando- 
se o comando "ctrl+f" a partir da lista completa dos trabalhos disponível na página eletrônica de cada uma das edições pesquisadas, o que permitiu localizar os termos tanto nos títulos, quanto nas palavras-chave. Excepcionalmente, como a lista total dos trabalhos do VI ENPEC não estava disponível na página do evento, a procura ocorreu por meio da ferramenta de busca geral, com a qual foi possível pesquisar partes do título, resumo e/ou palavras-chave. A página do VII ENPEC, por sua vez, facultava o acesso à lista integral dos trabalhos, mas a busca pelo comando "ctrl+f", vale salientar, resultava na identificação dos termos apenas nos títulos dos trabalhos.

Tabela 1. Revistas nas quais foram localizados trabalhos sobre a Teoria dos Campos Conceituais no ensino de ciências de acordo com o conceito Qualis e a quantidade de artigos selecionados

\begin{tabular}{|c|c|c|}
\hline Qualis & Revista & $\begin{array}{l}\text { Quantidade de artigos } \\
\text { selecionados }\end{array}$ \\
\hline \multirow{4}{*}{ A1 } & Ciência \& Educação & 2 \\
\hline & Educación Química & 1 \\
\hline & Enseñanza de las Ciencias & 1 \\
\hline & International Journal of Science Education & 1 \\
\hline \multirow{8}{*}{$\mathrm{A} 2$} & Amazônia - Revista de Educação em Ciências e Matemáticas & 2 \\
\hline & Educação Unisinos & 2 \\
\hline & Ensino, Saúde e Ambiente & 1 \\
\hline & Investigações em Ensino de Ciências & 8 \\
\hline & Revista Electrónica de Enseñanza de Las Ciencias & 5 \\
\hline & Revista Brasileira de Ensino de Ciência e Tecnologia & 5 \\
\hline & Revista Brasileira de Pesquisa em Educação em Ciências & 1 \\
\hline & Revista Electrónica de Investigación en Educación en Ciencias & 5 \\
\hline \multirow{3}{*}{ B1 } & Experiências em Ensino de Ciências & 6 \\
\hline & Góndola, Enseñanza y Aprendizaje de las Ciencias & 3 \\
\hline & Revista Ciências \& Ideias & 1 \\
\hline $\mathrm{B} 2$ & Ciências \& Cognição & 1 \\
\hline
\end{tabular}

Como o objetivo da busca foi localizar a maior quantidade de pesquisas abordando a temática, não foram selecionados apenas os trabalhos localizados pelo título ou palavras-chave, mas também pela leitura dos resumos. Quando os artigos localizados não possuíam informações suficientes em seus resumos, procedemos com a leitura parcial dos demais tópicos de modo a confirmar sua pertinência à temática desta pesquisa, como sugere a regra da exaustividade proposta por Bardin (1977). Além disso, procuramos seguir a regra da homogeneidade que, se mantida para todos os trabalhos, favorece a elaboração de categorias de inclusão e exclusão para os trabalhos (Bardin, 1977).

Após a estruturação do corpus, mapeamos os trabalhos encontrados segundo dados quantitativos gerais com relação aos seguintes aspectos: ano de publicação; país 
em que a pesquisa foi realizada (no caso dos artigos); região do Brasil (para as pesquisas nacionais); autores e suas instituições de origem; área das ciências naturais e nível de ensino para o qual o trabalho estava voltado.

Em seguida, analisamos as informações presentes nos trabalhos a fim de caracterizar o emprego da TCC de Vergnaud pelos pesquisadores. Dessa maneira, foi possível determinar as categorias em que melhor se enquadrariam os trabalhos. Cabe ressaltar que, uma vez identificada mais de uma categoria em um mesmo trabalho, estabelecemos a característica mais predominante como premissa para a sua classificação em uma única categoria.

\section{Resultados e discussão}

Após os procedimentos de busca foram selecionados 45 artigos publicados nos periódicos analisados e 21 trabalhos apresentados nos ENPEC, totalizando 66 pesquisas voltadas à temática, as quais serão referidas ao longo desta discussão pela indicação numérica (códigos com números entre colchetes) correspondente na lista constante na Figura 1, a qual exibe as referências completas de todas as pesquisas selecionadas em ordem cronológica.

\begin{tabular}{|l|l|}
\hline [1] & $\begin{array}{l}\text { Bueno Filho, M. A., Fernandez, C., \& Marzorati, L. (2007). Detecção dos esquemas de ação na } \\
\text { perspectiva da teoria dos campos conceituais relativos à representação química em alunos do } \\
\text { Ensino Superior. In VI Encontro Nacional de Pesquisa em Educação em Ciências. Florianópolis, SC. }\end{array}$ \\
\hline [2] & $\begin{array}{l}\text { Lima, A. R. F., \& Teixeira, F. M. (2007). Atividade interdisciplinar no ensino de ciências. In VI } \\
\text { Encontro Nacional de Pesquisa em Educação em Ciências. Florianópolis, SC. }\end{array}$ \\
\hline [3] & $\begin{array}{l}\text { Serrano, A., Konzen, D. A. K., \& Moreira, M. A. (2007). Do uso de representações simbólicas e } \\
\text { seus atributos no aprendizado de gases: Evolução conceitual por aprendizagem significativa, de um } \\
\text { perfil conceitual ou de representações e seus invariantes? In VI Encontro Nacional de Pesquisa em } \\
\text { Educação em Ciências. Florianópolis, SC. }\end{array}$ \\
\hline [4] & $\begin{array}{l}\text { Cudmani, L. C., \& Pesa, M. A. (2008). La evolución de los significados de los conceptos científicos } \\
\text { en relación con la estructura cognitiva de los estudiantes. Ciência \& Educação, 14(3), 365-380. } \\
\text { https://doi.org/10.1590/S1516-73132008000300001 }\end{array}$ \\
\hline [5] & $\begin{array}{l}\text { Grings, E. T. O., Sahelices, M. C. C., \& Moreira, M. A. (2008a). Avanços e retrocessos dos alunos } \\
\text { no campo conceitual da Termodinâmica. Revista Electrónica de Enseñanza de Las Ciencias, 7(1), } \\
\text { 23-46. }\end{array}$ \\
\hline [6] & $\begin{array}{l}\text { Grings, E. T. O., Sahelices, M. C. C., \& Moreira, M. A. (2008b). Uma proposta didática para abordar } \\
\text { o conceito de temperatura a partir de situações, à luz da teoria dos campos conceituais de Vergnaud. } \\
\text { Revista Brasileira de Ensino de Ciência e Tecnologia, 2(1), 1-21. https://doi.org/10.3895/S1982- } \\
873 X 2008000100001\end{array}$ \\
\hline [7] & $\begin{array}{l}\text { Silveira, A. V. C. (2008). O conceito de simetria na Física: significados para alunos do ensino } \\
\text { fundamental, médio e superior. Experiências em Ensino de Ciências, 3(3), 41-53. }\end{array}$ \\
\hline [8] & $\begin{array}{l}\text { Acioly-Régnier, N. M., \& Monin, N. (2009). Da teoria dos campos conceituais à didática profissional } \\
\text { para a formação de professores: Contribuição da psicologia e da sociologia para a análise de práticas } \\
\text { pedagógicas. Educação Unisinos, 13(1), 5-16. https://doi.org/10.4013/edu.2009.131.01 }\end{array}$ \\
\hline
\end{tabular}

Figura 1. Lista com as referências das pesquisas selecionadas em ordem cronológica precedidas de seus respectivos códigos de identificação (continua) 


\begin{tabular}{|c|c|}
\hline [9] & $\begin{array}{l}\text { Andrade Neto, A. S., Raupp, D., \& Moreira, M. A. (2009). A evolução histórica da linguagem } \\
\text { representacional química: Uma interpretação baseada na teoria dos campos conceituais. In VII } \\
\text { Encontro Nacional de Pesquisa em Educação em Ciências. Florianópolis, SC. }\end{array}$ \\
\hline [10] & $\begin{array}{l}\text { Bolfe, L. E. R., \& Barlette, V. E. (2009). Ensino de conceitos de física térmica a partir de } \\
\text { situações: Uma aproximação aos invariantes operatórios de Vergnaud. In VII Encontro Nacional } \\
\text { de Pesquisa em Educação em Ciências. Florianópolis, SC. }\end{array}$ \\
\hline [11] & $\begin{array}{l}\text { Covaleda, R., Moreira, M. A., \& Sahelices, M. C. C. (2009). Los conceptos de sistema y equilibrio } \\
\text { en el proceso de enseñanza/aprendizaje de la Mecánica y Termodinámica. Posibles invariantes } \\
\text { operatorios. Revista Electrónica de Enseñanza de Las Ciencias, 8(2), 722-744. }\end{array}$ \\
\hline [12] & $\begin{array}{l}\text { Escudero, C., \& Jaime, E. A. (2009). Conocimientos-en-acción: Un estudio acerca de la } \\
\text { integración de las fuerzas y la energía en cuerpo rígido. Investigações em Ensino de Ciências, } \\
\text { 14(1),114-133. }\end{array}$ \\
\hline [13] & $\begin{array}{l}\text { Fanaro, M. A., Otero, M. R., \& Moreira, M. A. (2009). Teoremas-en-acto y conceptos-em-acto } \\
\text { en dos situaciones relativas a la noción de sistema cuántico. Revista Brasileira de Pesquisa em } \\
\text { Educação em Ciências, 9(3),1-19. }\end{array}$ \\
\hline [14] & $\begin{array}{l}\text { Krey, I., \& Moreira, M. A. (2009). Implementación y evaluación de una propuesta de enseñanza } \\
\text { para el tópico física de partículas en una disciplina de estructura de la materia basada en la teoría } \\
\text { de los campos conceptuales de Vergnaud. Revista Electrónica de Enseñanza de Las Ciencias, } \\
\text { 8(3), 812-832. }\end{array}$ \\
\hline [15] & $\begin{array}{l}\text { Moreira, M. A., \& Sperling, C. S. (2009). Mapas conceptuales y aprendizaje significativo: ¿ Una } \\
\text { correlación necessária? Experiências em Ensino de Ciências, 4(3), 91-100. }\end{array}$ \\
\hline [16] & $\begin{array}{l}\text { Raupp, D., Serrano, A., \& Moreira, M. A. (2009). Desenvolvendo habilidades visuoespaciais: } \\
\text { uso de software de construção de modelos moleculares no ensino de isomeria geométrica em } \\
\text { química. Experiências em Ensino de Ciências, 4(1), 65-78. }\end{array}$ \\
\hline [17] & $\begin{array}{l}\text { Brandão, R. V., Araujo, I. S., \& Veit, E. A. (2010). Concepções e dificuldades dos professores de } \\
\text { Física no campo conceitual da modelagem científica. Revista Electrónica de Enseñanza de Las } \\
\text { Ciencias, 9(3), 669-695. }\end{array}$ \\
\hline [18] & $\begin{array}{l}\text { Otero, M. R. (2010). La Notion de Situation: analysée depuis la Théorie des Champs Conceptuels, } \\
\text { la Théorie des Situations, la Dialectique Outil-Object et la Théorie Anthropologique du } \\
\text { Didactique. Revista Electrónica de Investigación en Educación en Ciencias, 5(1), 42-53. }\end{array}$ \\
\hline [19] & $\begin{array}{l}\text { Rocha, C. R., Herscovitz, V. E., \& Moreira, M. A. (2010). Introdução à Mecânica Quântica: } \\
\text { Uma proposta de minicurso para o ensino de conceitos e postulados fundamentais. Revista } \\
\text { Brasileira de Ensino de Ciência e Tecnologia, 3(1), 1-15. https://doi.org/10.3895/S1982- } \\
\text { 873X2010000100001 }\end{array}$ \\
\hline [20] & $\begin{array}{l}\text { Engel, V., \& Serrano, A. (2011). Evidência de reconstrução interna de representações externas } \\
\text { computacionais animadas como representações internas e invariantes operatórios: Um estudo } \\
\text { de caso da produção de gestos descritivos em física mecânica. In VIII Encontro Nacional de } \\
\text { Pesquisa em Educação em Ciências, Campinas, SP. }\end{array}$ \\
\hline [21] & $\begin{array}{l}\text { Figueroa, P. S., \& Otero, M. R. (2011). Nociones fundamentales de la Teoría de los Campos } \\
\text { Conceptuales. Revista Electrónica de Investigación en Educación en Ciencias, 6(1), 1-14. }\end{array}$ \\
\hline [22] & $\begin{array}{l}\text { Jaime, E. A., \& Escudero, C. (2011). El trabajo experimental como posible generador de } \\
\text { conocimiento en enseñanza de la física. Enseñanza de las Ciencias, 29(3), 371-380. }\end{array}$ \\
\hline
\end{tabular}

Figura 1. Lista com as referências das pesquisas selecionadas em ordem cronológica precedidas de seus respectivos códigos de identificação (continua) 


\begin{tabular}{|c|c|}
\hline [23] & $\begin{array}{l}\text { Matos, S. A., \& Martins, C. M. C. (2011). O ensino por investigação como campo conceitual na } \\
\text { Teoria de Vergnaud. In VIII Encontro Nacional de Pesquisa em Educação em Ciências. Campinas, SP. }\end{array}$ \\
\hline [24] & $\begin{array}{l}\text { Oliveira, V. V., Teodoro Júnior, R. D. S., Silva, L. G., \& Carvalho Júnior, G. D. (2011). Análise de } \\
\text { situação: Apropriação de conceitos científicos. In VIII Encontro Nacional de Pesquisa em Educação } \\
\text { em Ciências. Campinas, SP. }\end{array}$ \\
\hline [25] & $\begin{array}{l}\text { Mackedanz, L. F., \& Araújo, R. (2011). Por que sentimos frio? - Investigação de invariantes } \\
\text { operatórios nos conceitos de termodinâmica entre estudantes do primeiro ano universitário. In VIII } \\
\text { Encontro Nacional de Pesquisa em Educação em Ciências. Campinas, SP. }\end{array}$ \\
\hline [26] & $\begin{array}{l}\text { Viveiros, E. R., \& Camargo, E. P. (2011a). Deficiência visual e educação científica: orientações } \\
\text { didáticas com um aporte na neurociência cognitiva e teoria dos campos conceituais. Góndola, } \\
\text { Enseñanza y Aprendizaje de las Ciencias, 6(2), 25-50. https://doi.org/10.14483/23464712.5095 }\end{array}$ \\
\hline [27] & $\begin{array}{l}\text { Viveiros, E. R., \& Camargo, E. P. (2011b). A biônica no ensino de física: uma tecnologia assistiva } \\
\text { utilizando uma interface cérebro computador para controlar uma unidade robótica. In VIII Encontro } \\
\text { Nacional de Pesquisa em Educação em Ciências. Campinas, SP. }\end{array}$ \\
\hline [28] & $\begin{array}{l}\text { Viveiros, E. R., \& Camargo, E. P. (2011c). A pesquisa em neurociência e suas implicações para o } \\
\text { ensino de ciências: Contribuições para o ensino de física em deficientes visuais. In VIII Encontro } \\
\text { Nacional de Pesquisa em Educação em Ciências. Campinas, SP. }\end{array}$ \\
\hline [29] & $\begin{array}{l}\text { Hilger, T., \& Oliveira, A. (2012). O problema dos falsos teoremas-em-ação sobre a força de atrito na } \\
\text { disciplina de física geral para graduação. Revista Brasileira de Ensino de Ciência e Tecnologia, 5(1), } \\
\text { 54-70. https://doi.org/10.3895/S1982-873X2012000100004 }\end{array}$ \\
\hline [30] & $\begin{array}{l}\text { Toigo, A. M., Moreira, M. A., \& Costa, S. S. C. (2012). Revisión de la literatura sobre el uso de mapas } \\
\text { conceptuales como estrategia didáctica y de evaluación. Investigações em ensino de ciências, 17(2), } \\
\text { 305-339. }\end{array}$ \\
\hline [31] & $\begin{array}{l}\text { Campos, A., \& Ricardo, E. C. (2013). O processo de conceitualização do Princípio de Conservação } \\
\text { da Energia Mecânica. In IX Encontro Nacional de Pesquisa em Educação em Ciências. Águas de } \\
\text { Lindóia, SP. }\end{array}$ \\
\hline [32] & $\begin{array}{l}\text { Carvalho Júnior, G. D., Aguiar Júnior, O. G., \& Bruno, S. (2013). Invariantes operatórios utilizados } \\
\text { por estudantes do ensino médio: O caso da transição entre conceitos clássicos e relativísticos. In IX } \\
\text { Encontro Nacional de Pesquisa em Educação em Ciências. Águas de Lindóia, SP. }\end{array}$ \\
\hline [33] & $\begin{array}{l}\text { Henríquez, A. L., Gallardo, C. J., \& Pinto, W. L. D. (2013). Aprendizaje de los conceptos de fuerza y } \\
\text { energía en estudiantes de ingeniería: Un estudio exploratorio. Revista Electrónica de Investigación en } \\
\text { Educación en Ciencias, 8(1), 14-23. }\end{array}$ \\
\hline [34] & $\begin{array}{l}\text { Parisoto, M. F., Moreira, M. A., \& Moro, J. T. (2013). Teoremas-em-ação e conceitos-em-ação na } \\
\text { física aplicada à medicina. Ensino, Saúde e Ambiente, 6(3), 114-128. https://doi.org/10.22409/ } \\
\text { resa2013.v6i3.a21146 }\end{array}$ \\
\hline [35] & $\begin{array}{l}\text { Sahelices, C. C., \& Villagrá, J. A. M. (2013). Principios de mecánica cuántica en la resolución de } \\
\text { problemas de estructuras atómicas en estudiantes de química. Experiências em Ensino de Ciências, } \\
\text { 8(1),1-16. }\end{array}$ \\
\hline [36] & $\begin{array}{l}\text { Scheffler, G. L., \& Del Pino, J. C. (2013). A teoria dos campos conceituais de Vergnaud e o ensino da } \\
\text { radioatividade. Experiências em Ensino de Ciências, 8(1), 29-46. }\end{array}$ \\
\hline [37] & $\begin{array}{l}\text { Souza, E. S. R. (2013). Etnofísica, modelagem matemática, geometria... tudo no mesmo Manzuá. } \\
\text { Amazônia: Revista de Educação em Ciências e Matemáticas, 9(18), 99-112. https://doi.org/10.18542/ } \\
\text { amazrecm.v9i18.2026 }\end{array}$ \\
\hline
\end{tabular}

Figura 1. Lista com as referências das pesquisas selecionadas em ordem cronológica precedidas de seus respectivos códigos de identificação (continua) 


\begin{tabular}{|c|c|}
\hline [38] & $\begin{array}{l}\text { Tauceda, K. C., Del Pino, J. C., \& Nunes, V. M. N. (2013). O PIBID na formação inicial de } \\
\text { professores de ciências: Uma pesquisa no referencial dos campos conceituais de Vergnaud. In IX } \\
\text { Encontro Nacional de Pesquisa em Educação em Ciências. Águas de Lindóia, SP. }\end{array}$ \\
\hline [39] & $\begin{array}{l}\text { Tauceda, K. C., Nunes, V. M., \& Del Pino, J. C. (2013). O desenvolvimento de possíveis indicadores } \\
\text { de invariantes operatórios por estudantes do ensino médio na disciplina de biologia. Experiências } \\
\text { em Ensino de Ciências, 8(1), 98-110. }\end{array}$ \\
\hline [40] & $\begin{array}{l}\text { Brandão, R. V., Araujo, I. S., \& Veit, E. A. (2014). Um estudo de caso para dar sentido à tese de } \\
\text { que a modelagem científica pode ser vista como um campo conceitual. Revista Electrónica de } \\
\text { Investigación en Educación en Ciencias, 9(1), 1-21. }\end{array}$ \\
\hline [41] & $\begin{array}{l}\text { Castaño, G. C., Andrés, M. M., \& Villagrá, J. A. M. (2014). La teoría de los campos conceptuales: } \\
\text { Una exploración como referente en la formación de profesores de ciencias. Investigações em } \\
\text { Ensino de Ciências, 19(3), 553-563. }\end{array}$ \\
\hline [42] & $\begin{array}{l}\text { Pantoja, G. C. F., Moreira, M. A., \& Herscovitz, V. E. (2014). La enseñanza de conceptos } \\
\text { fundamentales de Mecánica Cuántica a alumnos de graduación en Física. Revista Electrónica de } \\
\text { Investigación en Educación en Ciencias, 9(1),22-39. }\end{array}$ \\
\hline [43] & $\begin{array}{l}\text { va, J. A., \& Sousa, C. M. S. G. (2014). O modelo ondulatório como estratégia de promoção da } \\
\text { lução conceitual em tópicos sobre a luz em nível Médio. Ciência \& Educação, 20(1), 23-41. } \\
\text { p://dx.doi.org/10.1590/1516-731320140010003 }\end{array}$ \\
\hline [44] & $\begin{array}{l}\text { nceda, K. C., \& Del Pino, J. C. (2014). Processos cognitivos e epistemologias da teoria dos } \\
\text { npos conceituais de Gérard Vergnaud, do ensino narrativo e do aprender a aprender. Ciências } \\
\text { Cognição, 19(2), 256-266. }\end{array}$ \\
\hline [45] & $\begin{array}{l}\text { Anjos, A. J. S., Sahelices, C. C., \& Moreira, M. A. (2015). As equações matemáticas no ensino de } \\
\text { Física: Uma análise de conteúdos em livros didáticos de Física. Revista Electrónica de Enseñanza } \\
\text { de las Ciencias, 14(3), 312-325. }\end{array}$ \\
\hline [46] & $\begin{array}{l}\text { Campos, A., \& Ricardo, E. C. (2015). A dinâmica newtoniana como obstáculo para a aprendizagem. } \\
\text { In X Encontro Nacional de Pesquisa em Educação em Ciências. Águas de Lindóia, SP. }\end{array}$ \\
\hline [47] & $\begin{array}{l}\text { valho Júnior, G. D. (2015). O esquema de movimento como organizador da ação em mecânica } \\
\text { sica e relativística. Investigações em Ensino de Ciências, 20(3), 205-235. }\end{array}$ \\
\hline [48] & $\begin{array}{l}\text { Moreira, L. P. B., \& Andrade Neto, A. S. (2015). Ganho cognitivo no estudo de circuitos elétricos } \\
\text { com utilização de ferramentas hiperculturais. In X Encontro Nacional de Pesquisa em Educação } \\
\text { em Ciências, Águas de Lindóia, SP. }\end{array}$ \\
\hline [49] & $\begin{array}{l}\text { Tauceda, K. C., Del Pino, J. C., Nunes, L. M., \& Witt, N. (2015). A alfabetização científica em } \\
\text { situações-problema: Um conceito norteador para uma metodologia investigativa na formação } \\
\text { continuada dos professores de química. In X Encontro Nacional de Pesquisa em Educação em } \\
\text { Ciências, Águas de Lindóia, SP. }\end{array}$ \\
\hline [50] & $\begin{array}{l}\text { Andrade, P. V. C. C., \& Acioly-Régnier, N. M. (2016). Utilização de um dispositivo pedagógico } \\
\text { tecnológico híbrido na formação de professores na França. Educação Unisinos, 20(1), 117-128. } \\
\text { http://dx.doi.org/10.4013/edu.2016.201.12 }\end{array}$ \\
\hline [51] & $\begin{array}{l}\text { Bravo, S., \& Pesa, M. A. (2016). Evaluación del aprendizaje de interferencia y difracción de la luz } \\
\text { en el laboratorio de física. Investigações em Ensino de Ciências, 21(2), 68-104. }\end{array}$ \\
\hline [52] & $\begin{array}{l}\text { Schittler, D., \& Moreira, M. A. (2016). Física Moderna e Contemporânea no primeiro ano do } \\
\text { Ensino Médio: Laser de Rubi um exemplo de Unidade de Ensino Potencialmente Significativa. } \\
\text { Revista Brasileira de Ensino de Ciência e Tecnologia, 9(3), 1-24. http://dx.doi.org/10.3895/rbect. } \\
\text { v9n3.2407 }\end{array}$ \\
\hline
\end{tabular}

Figura 1. Lista com as referências das pesquisas selecionadas em ordem cronológica precedidas de seus respectivos códigos de identificação (continua) 


\begin{tabular}{|c|c|}
\hline [53] & $\begin{array}{l}\text { oni, K. T., \& Laburú, C. E. (2017). Diversidade Representacional e teoremas-em-ação: Um } \\
\text { studo de caso a respeito da construção de conhecimento de um estudante no campo conceitual } \\
\text { torial. In XI Encontro Nacional de Pesquisa em Educação em Ciências. Florianópolis, SC. }\end{array}$ \\
\hline [54] & $\begin{array}{l}\text { Calheiro, L. B., \& Del Pino, J. C. (2017). O estudo da luz visível no ensino médio a partir do } \\
\text { campo conceitual de Vergnaud. In XI Encontro Nacional de Pesquisa em Educação em Ciências. } \\
\text { Florianópolis, SC. }\end{array}$ \\
\hline [55] & $\begin{array}{l}\text { leidemann, L. A., Araujo, I. S., \& Veit, E. A. (2017). Um estudo de caso explanatório sobre o } \\
\text { esenvolvimento de atividades experimentais com enfoque no processo de modelagem científica } \\
\text { ara o ensino de Física. Revista Brasileira de Ensino de Ciência e Tecnologia, 10(3), 379-405. } \\
\text { ttp://dx.doi.org/10.3895/rbect.v10n3.5672 }\end{array}$ \\
\hline [56] & $\begin{array}{l}\text { ascimento, E. D., \& Carvalho Junior, G. D. (2017). Quando a cor é uma vibração em uma corda: } \\
\text { uscando invariantes operatórios utilizados por estudantes cegos na interação com objetos físicos. } \\
\text { XI Encontro Nacional de Pesquisa em Educação em Ciências. Florianópolis, SC. }\end{array}$ \\
\hline [57] & $\begin{array}{l}\text { Pantoja, G. C. F. (2017). A study on pre-service physics teachers' conceptualization on elementary } \\
\text { quantum mechanics. Investigações em Ensino de Ciências, 22(2), 120-138. }\end{array}$ \\
\hline [58] & $\begin{array}{l}\text { Tauceda, K. C., \& Del Pino, J. C. (2017). Relação da teoria pedagógica com a prática docente: } \\
\text { Contribuições dos campos conceituais para a formação de professores de ciências através do } \\
\text { PIBID. In XI Encontro Nacional de Pesquisa em Educação em Ciências. Florianópolis, SC. }\end{array}$ \\
\hline [59] & $\begin{array}{l}\text { Antonello, S. B., Garcia, I. K. G., Santarosa, M. C. P. S., Baggio, G. H. C., \& de Lopes, J. L. L. } \\
\text { (2018). Possíveis indicadores de invariantes operatórios pertinentes aos campos conceituais da } \\
\text { eletrodinâmica e proporcionalidade no ensino médio integrado. Revista Ciências \& Ideias, 9(1), } \\
\text { 51-75. http://dx.doi.org/10.22047/2176-1477/2018.v9i1.827 }\end{array}$ \\
\hline$[60]$ & $\begin{array}{l}\text { raque, I., Montilla, L., Meleán, R., \& Arrieta, X. Entornos virtuales para el aprendizaje: Una } \\
\text { irada desde la teoría de los campos conceptuales. Góndola, enseñanza y aprendizaje de las } \\
\text { encias, 13(1), 86-100, 2018. http://dx.doi.org/10.14483/23464712.11721 }\end{array}$ \\
\hline [61] & $\begin{array}{l}\text { Boni, K. T., \& Laburú, C. E. (2018). Conceitualização e metacognição em Ciências e Matemática: } \\
\text { Pressupostos teóricos de um instrumento analítico. Amazônia: Revista de Educação em Ciências } \\
\text { e Matemáticas, 14(29), 177-192. }\end{array}$ \\
\hline [62] & $\begin{array}{l}\text { anaro, M. A., \& Elgue, M. (2018). La conceptualización de la experiencia de la doble rendija a } \\
\text { artir del enfoque de caminos múltilples de Feyman. Góndola, Enseñanza y Aprendizaje de las } \\
\text { iencias, 13(2), 272-290. http://dx.doi.org/10.14483/23464712.12466 }\end{array}$ \\
\hline [63] & $\begin{array}{l}\text { erreira, B., J., V., Andrés, Z., \& Maite, M. (2018). Un módulo con simulaciones interactivas } \\
\text { idácticas para la comprensión conceptual de un modelo físico en un trabajo de laboratorio de } \\
\text { sica en la universidad. Investigações em Ensino de Ciências, 23(1), 183-199. }\end{array}$ \\
\hline$[64]$ & $\begin{array}{l}\text { Heidemann, L. A., Araujo, I. S., \& Veit, E. A. (2018). Dificuldades e avanços no domínio do } \\
\text { campo conceitual da modelagem didático-científica: Um estudo de caso em uma disciplina de } \\
\text { física experimental. Investigações em ensino de ciências, 23(2), 352-382. }\end{array}$ \\
\hline [65] & $\begin{array}{l}\text { Machado, J., \& Braga, M. (2018). Secondary students' modelling conceptualisation in situations } \\
\text { related to particle dynamics: A clinical perspective. International Journal of Science Education, } \\
\text { 40(13), 1606-1628. https://doi.org/10.1080/09500693.2018.1494394 }\end{array}$ \\
\hline [66] & $\begin{array}{l}\text { Silva, R. M.S. D., Nascimento, M.G., Cunha, R.L.O. R., \& Bueno Filho, M. A. (2018). Construcción } \\
\text { de relaciones entre conceptos relativos al campo estructural y al campo da Cinética Química } \\
\text { por estudiantes de pregrado en la acepción de la teoría de los campos conceptuales. Educación } \\
\text { química, 29(3), 48-60. https://doi.org/10.22201/fq.18708404e.2018.1.63720 }\end{array}$ \\
\hline
\end{tabular}

Figura 1. Lista com as referências das pesquisas selecionadas em ordem cronológica precedidas de seus respectivos códigos de identificação (continuação)

Fonte: Autoria própria. 
A Figura 2 a seguir sintetiza os resultados quantitativos gerais, especialmente a frequência dos trabalhos identificados com relação ao ano de publicação; país em que a pesquisa foi realizada (no caso dos artigos); região do Brasil; instituições de origem dos autores; área das ciências naturais e nível de ensino para o qual o trabalho estava voltado. É importante ressaltar que na determinação da frequência de trabalhos quanto à região brasileira, consideramos a região do primeiro autor para trabalhos com autores de diferentes regiões. Vale destacar, ainda para esta categoria, que a quantidade máxima considerada foi de 51 trabalhos, uma vez que, por questões óbvias, as pesquisas internacionais não se enquadravam nesta contagem.

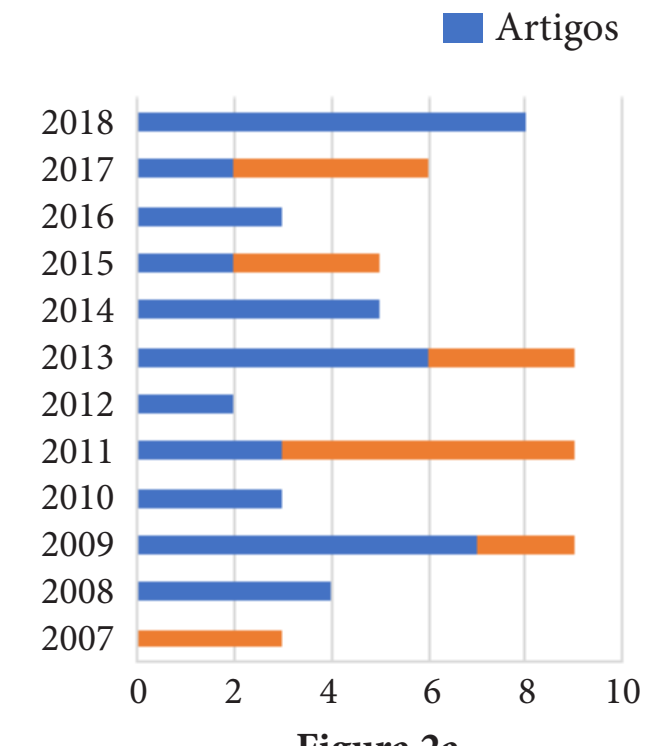

Figura 2a

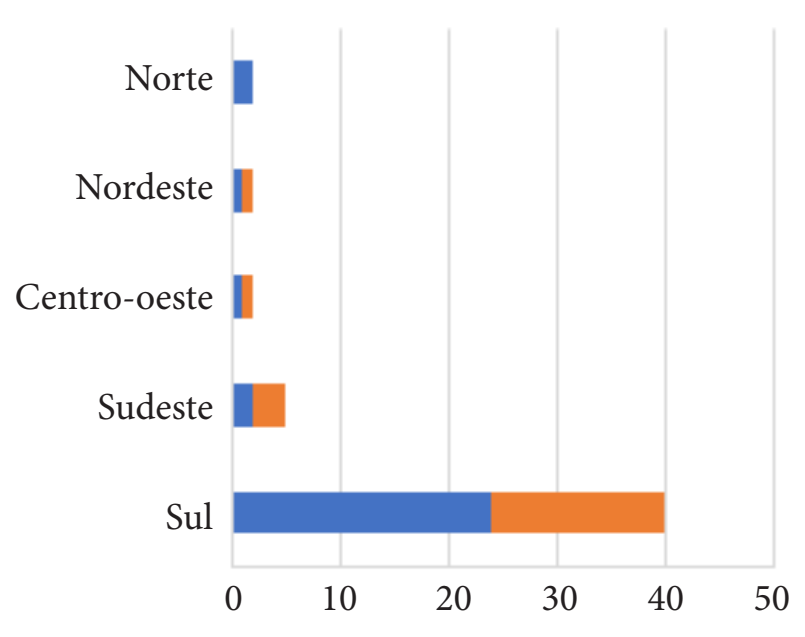

Figura 2c

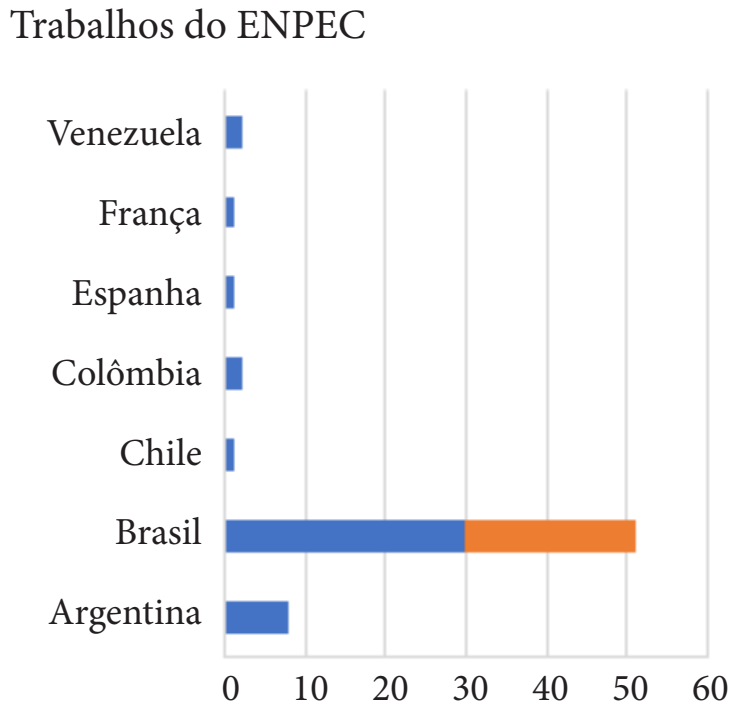

Figura $2 b$

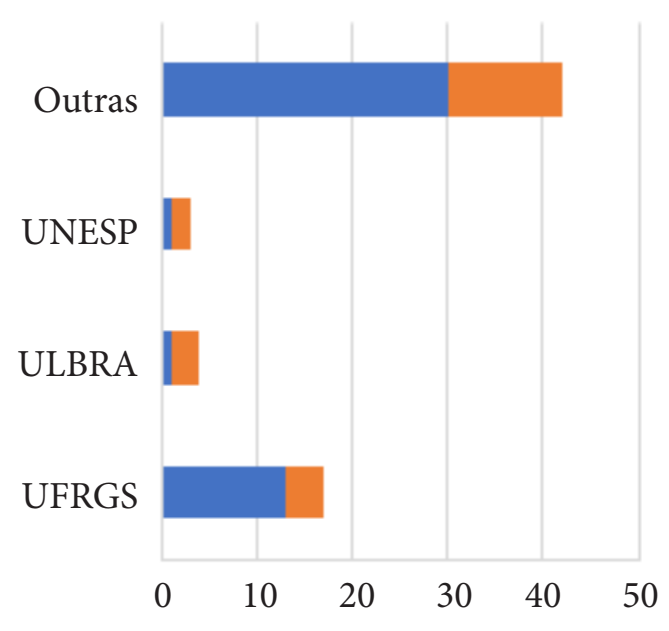

Figura 2d

Figura 2. Distribuição dos trabalhos selecionados sobre a Teoria dos Campos Conceituais no ensino de ciências no evento e periódicos pesquisados em relação à distribuição por: (2a) ano pesquisado, (2b) país, (2c) região brasileira, (2d) instituição do autor principal (continua)

Fonte: autoria própria. 


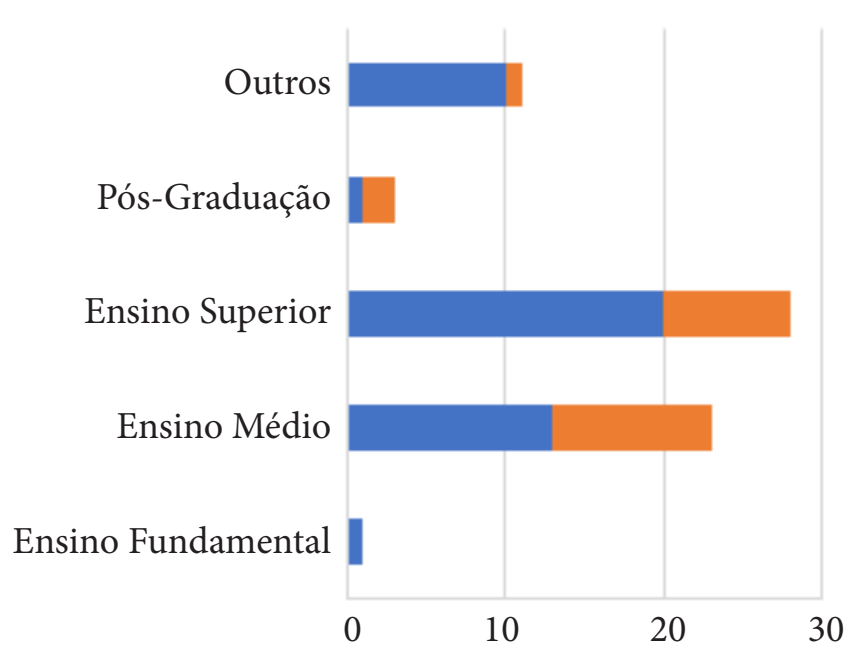

Figura 2e

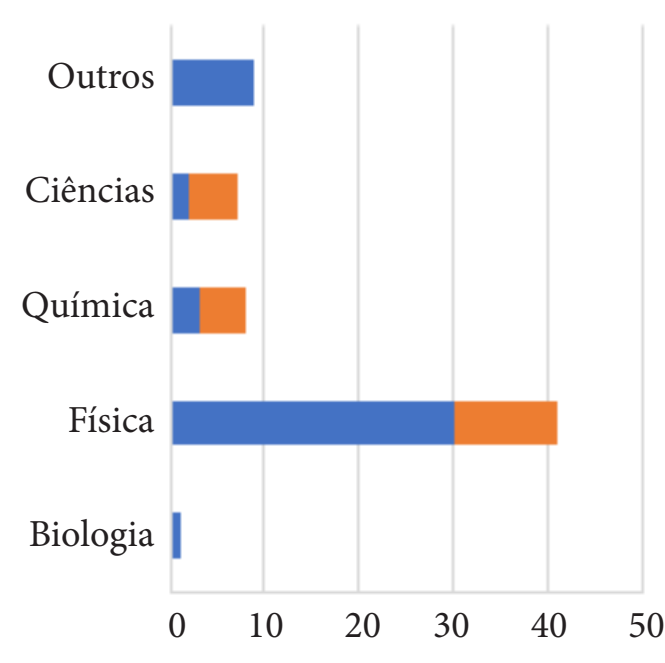

Figura $2 f$

Figura 2. Distribuição dos trabalhos selecionados sobre a Teoria dos Campos Conceituais no ensino de ciências no evento e periódicos pesquisados em relação à distribuição por: (2e) nível de ensino e (2f) área das ciências naturais (continuação)

Fonte: autoria própria.

A partir da Figura 2 é possível observar que embora o número de artigos tenha se mostrado superior dentro do período analisado, a amostra selecionada no ENPEC também mostrou-se significativa, uma vez que a busca de artigos teve maior fonte de coleta. Os trabalhos publicados nos ENPEC mostram uma regularidade de publicações sobre a temática, com pelo menos duas publicações por edição pesquisada. Por outro lado, a quantidade identificada no evento corresponde a apenas $0,32 \%$ do total de trabalhos apresentados nas seis edições investigadas (6.302 trabalhos). A distribuição temporal mostrou também que o ano de 2018 foi o de maior número de publicações nos periódicos, demonstrando quantidade considerável no ano mais recente do recorte de tempo adotado.

Verificamos que o Brasil apresenta o maior número de artigos em relação aos demais países. Obviamente, publicações do ENPEC não podem ser consideradas nesse parâmetro de análise, tendo em vista que, embora abarque trabalhos de pesquisadores de outros países, tem suas atas publicadas em âmbito nacional.

Os dados apontam também os autores da região Sul como os detentores do maior número de publicações sobre a temática e a liderança da Universidade Federal do Rio Grande do Sul (UFRGS) em relação às demais instituições. Sobre esse aspecto buscou-se, ainda, investigar os autores dos trabalhos selecionados de modo a conhecer os principais pesquisadores ligados à temática e suas linhas de pesquisa, bem como verificar a presença de grupos de estudo consolidados sobre a temática e suas respectivas instituições. Nesse sentido, são dignos de nota os pesquisadores Marco Antônio Moreira e José Cláudio Del Pino, ambos da UFRGS, com 15 e 7 trabalhos encontrados nesta revisão (33\% do total identificado), respectivamente. 
Quanto ao nível de ensino tomado como objeto nas pesquisas, observamos propostas destinadas a diferentes níveis, com maior frequência o Ensino Superior, para o qual foram identificadas 28 pesquisas voltadas tanto à análise dos conhecimentos científicos dos graduandos, como à formação de professores, em virtude de suas contribuições para o desenvolvimento cognitivo (Moreira, 2002), o aprendizado de competências dos alunos (Moreira, 2009; Vergnaud, 2013) e a busca de compreensão das filiações e rupturas na formação do conhecimento imprescindíveis a esse nível de ensino (Vergnaud, 2017a).

A respeito da escassez de pesquisas voltadas ao público do Ensino Fundamental, o trabalho de Viecheneski, Lorenzetti e Carletto (2012) cita diferentes estudos que apresentam problemáticas que podem ser apontadas como justificativas para tal resultado. Algumas delas baseiam-se nas concepções que alguns professores têm a respeito dos processos de ensino e aprendizagem nesse nível de ensino, pois avaliam que alunos nesta faixa etária não apresentam condições de compreender os conhecimentos científicos. Além disso, os autores mencionam a insegurança de muitos professores no desenvolvimento de um estudo minucioso com os alunos do Ensino Fundamental, tendo em vista que sua formação inicial não lhes forneceu uma preparação necessária para a abordagem da disciplina Ciências desse nível de ensino.

Consideramos também relevante observar a distribuição dos trabalhos selecionados em suas respectivas áreas dentro das ciências naturais: biologia, física, química e ciências (Consideramos na categoria "ciências" os trabalhos em que os autores não mencionaram uma área específica dentro das ciências naturais e/ou aqueles voltados à disciplina Ciências para o ensino fundamental), a qual apontou predominância de pesquisas direcionadas ao ensino de física. Na categoria "outros" foram alocados trabalhos não diretamente relacionados às ciências naturais, como pedagogia e psicologia, por exemplo. Ressalta-se, ainda, que embora a TCC tenha sido elaborada incialmente com o intuito de compreender a aprendizagem matemática, a mesma, atualmente, estende-se às demais áreas das ciências por possibilitar um estudo mais aprofundado de competências complexas dos estudantes.

Além das informações gerais, a partir da leitura dos textos foi possível obter importantes considerações sobre a TCC, permitindo alcançar uma melhor compreensão acerca de suas potencialidades no ensino de ciências, mostrando ainda que são variadas as abordagens presentes na literatura no que se refere aos estudos realizados e às justificativas para tal. Assim, os trabalhos foram analisados de acordo com o foco dado à TCC, o que permitiu organizá-los nas seguintes categorias, que equivalem às principais temáticas apresentadas:

1. Ponderações sobre a TCC e suas implicações no ensino de ciências: Trazem as principais características e fundamentos da teoria;

2. Atividades centradas em situações-problema: referem-se à resolução de problemas práticos em situações reais, a fim de analisar os desdobramentos de 
pensamento usados pelos estudantes para o estabelecimento de relações entre os conceitos abordados;

3. Análise dos invariantes operatórios: dizem respeito à identificação do conjunto de invariantes associados aos conceitos que podem ser identificados e utilizados pelos sujeitos para considerar e dominar as situações relacionadas a eles;

4. Uso das tecnologias na promoção da aprendizagem de conceitos científicos sob a ótica da TCC: fazem alusão ao uso das tecnologias no auxílio ao ensino e à aprendizagem de ciências;

5. Formação de professores e as contribuições da TCC: abordam análises das contribuições dos campos conceituais para a formação de professores.

\section{Ponderações sobre a TCC e suas implicações no ensino de ciências}

A partir da análise dos objetivos delineados nas pesquisas, verificou-se estudos teóricos dedicados a caracterizar a TCC e a discutir suas implicações no ensino de ciências $[4 ; 18 ; 21 ; 26 ; 30 ; 60 ; 61]$. Nesse sentido, os trabalhos alocados nesta categoria abordam, primordialmente, a reflexão de aspectos fundamentais da teoria $[4 ; 18 ; 21]$ e de propostas educacionais elaboradas nos seus moldes [26; 60]. Ademais, incluímos nesta categoria uma revisão de literatura sobre mapas conceituais [30] e uma investigação sobre um instrumento de análise do processo de explicitação de estudantes [61], ambas ancoradas na TCC como referencial de análise.

Cudmani e Pesa (2008) buscaram conhecer o processo de evolução conceitual na perspectiva da teoria do significado de Mario Bunge e da teoria cognitivista de Gérard Vergnaud [4]. O trabalho demonstrou o potencial da TCC como fundamentação teórica para a compreensão da aprendizagem em termos de conceitos científicos e técnicos, visto que se propõe a compreender os processos de construção do conhecimento, a partir do desempenho dos alunos em ação, evidenciando as relevantes contribuições que tais teorias fornecem ao ensino de ciências e também à pesquisa nessa área.

Otero (2010), por sua vez, analisou a noção de situação considerando diferentes referenciais teóricos, entre eles a TCC [18]. O autor apontou pontos semelhantes e divergentes em cada teoria a fim de oferecer a educadores a possibilidade de esboçar situações de aprendizagem fundadas em princípios didáticos e cognitivos. A noção de situação também foi foco de estudo no trabalho de Figueroa e Otero (2011), tanto quanto outras ideias fundamentais da TCC, como teoremas e conceitos-em-ação, a partir da apresentação de exemplos do campo da matemática [21]. Desse modo, a pesquisa oferece a pesquisadores meios de conhecer a teoria, bem como reconhecer suas possibilidades de aplicação a partir dos exemplos citados.

Além disso, outras pesquisas buscaram ponderar aspectos de propostas educacionais com diretrizes didático-pedagógicas para o ensino de ciências 
fundamentadas na TCC. Com esta premissa, Viveiros e Camargo (2011a) discutiram uma proposta de ensino direcionada a indivíduos com deficiência visual utilizando a teoria e seus prováveis benefícios [26]. Os autores buscaram conhecer as características epistemológicas do ensino de ciências, necessárias à elaboração de um protocolo semiótico e metodológico para a área fundamentado na inclusão. O estudo mostrou, portanto, que a TCC permite associar a semiótica a parâmetros cognitivos, levando em conta a tríade "Situação didática, Invariantes Operatórios e Representações".

De modo similar, Araque, Montilla, Meleán e Arrieta (2018) tiveram como objetivo pontuar elementos relacionados a metodologias e recursos de aprendizagem, assim como o papel de professores e alunos, em uma perspectiva de construção do conhecimento e processo educacional centrado na aprendizagem à luz da TCC [60]. Com isso, os autores demonstraram a necessidade de uma análise mais detalhada dos elementos presentes nos esquemas utilizados pelos alunos para a sua aprendizagem, os quais determinarão os métodos educativos.

Toigo, Moreira e Costa (2012) realizaram um levantamento bibliográfico sobre o uso de mapas conceituais na educação formal, seja como estratégia didática ou de avaliação, com posterior análise segundo princípios da Aprendizagem Significativa e da TCC [30]. Os autores elencaram que os mapas conceituais podem auxiliar a aprendizagem desde que o professor reconheça que o uso de forma isolada não permite verificar a evolução dos alunos e as suas dificuldades com relação ao conceito. Isso ocorre porque cada sujeito tem capacidades cognitivas individuais, isto é, o domínio de um dado campo conceitual pode ocorrer de maneiras diferentes para cada aluno, visto que é um processo lento e gradual que ocorre por meio de rupturas e continuidades nos conhecimentos.

Boni e Laburú (2018) construíram um instrumento didático a partir da reformulação do Modelo de Redescrição Representacional - que define variadas classes de explicitação dos estudantes - para verificar os níveis cognitivos pela identificação dos invariantes operatórios e invariantes predicativos de acordo com a TCC [61]. Nesse sentido, o instrumento apresentou-se como promissora ferramenta para o acompanhamento do desenvolvimento cognitivo do estudante durante a aprendizagem de conceitos científicos e oferecendo a oportunidade de elaboração de estratégias de ensino que favoreçam o processo de aprendizagem.

\section{Atividades centradas em situações-problema}

Com a leitura dos trabalhos foi possível verificar a frequência do uso de situaçõesproblema como objeto de estudo, evidenciando sua capacidade de potencializar o processo de conceitualização por meio do qual o aluno se desenvolve cognitivamente. Nesta categoria foram alocados 29 trabalhos, os quais tratam de iniciativas de implementação de problemas com vistas à aprendizagem conceitual. Cabe destacar que foram organizadas subcategorias com a finalidade de apresentar uma visão mais representativa das pesquisas, sobre as quais são apresentados os principais objetivos e 
considerações dos pesquisadores, da seguinte forma:

a) Detecção dos esquemas de ação relativos à aprendizagem de conceitos $[1 ; 7$; $12 ; 22 ; 42 ; 45 ; 55 ; 65 ; 66]$;

b) Análise dos avanços e obstáculos na aprendizagem de conceitos científicos [5; $10 ; 24 ; 33 ; 40 ; 57 ; 62]$;

c) Estudo da evolução conceitual e o enriquecimento das suas representações simbólicas $[3 ; 9 ; 31 ; 35 ; 36 ; 43 ; 51 ; 63 ; 64]$;

d) Introdução de conceitos científicos $[6 ; 19 ; 52]$;

e) Uso de mapas conceituais [15].

Verificou-se que as subcategorias relativas ao "estudo da evolução conceitual e o enriquecimento das representações simbólicas" e "detecção dos esquemas de ação relativos à aprendizagem de conceitos" foram as estratégias mais empregadas nas pesquisas desta categoria. De fato, a resolução de problemas possibilita o acompanhamento da evolução conceitual dos estudantes enriquecendo, assim, suas representações simbólicas.

A obtenção de conhecimento, na perspectiva da TCC, será determinada pelas situações apresentadas aos alunos, assim como pelas ações que ele realiza para a sua resolução (Souza, \& Fávero, 2002). É por meio do enfrentamento de situações que esse conhecimento se torna significativo para os alunos sendo, então, a ocasião oportuna para a promoção da evolução conceitual (Souza, \& Fávero, 2002). Nesse sentido, Vergnaud (2017a) explica que o enfrentamento de diferentes classes de problemas (desestabilização) permite aos estudantes criar filiações entre os seus conhecimentos prévios e os conceitos cientificamente aceitos, resultando, dessa forma, na evolução conceitual. Além disso, a partir da teoria propõe-se oferecer a possibilidade de compreensão dos processos implícitos à cognição, em especial, à construção de representações internas do sujeito (Andrés, Pesa, \& Villagrá, 2008).

Dos estudos sobre a evolução conceitual e o enriquecimento das representações simbólicas, destacamos a pesquisa de Scheffler e Del Pino (2013), com foco na análise das contribuições do uso da TCC no ensino de radioatividade e da evolução conceitual dos estudantes de um curso técnico em radiologia, por meio da qual puderam reconhecer os possíveis invariantes operatórios e delinear a evolução conceitual dos alunos, admitindo as proposições de mudança de perfil conceitual. Os autores ponderaram que é possível, por meio da implementação de situações-problema, acompanhar os estudantes durante sua aprendizagem, permitindo ao professor identificar os indícios de aprendizagem significativa através do mapeamento de sua evolução conceitual [36]. Assim, constatamos que a TCC apresenta-se como importante instrumento de planejamento didático, com o qual o professor tem a possiblidade de selecionar e analisar situações potencialmente significativas que permitam a identificação de dificuldades e/ou evolução conceitual dos estudantes. Com isso, poderá acompanhar o desenvolvimento da aprendizagem 
do sujeito-em-situação e fazer uso de métodos que favorecem a aprendizagem de seus alunos. De fato, a TCC fornece ao professor auxílio didático-metodológico ao privilegiar a compreensão da aprendizagem e o delineamento de estratégias que auxiliem os estudantes na evolução conceitual (Vergnaud, 2009).

Cabe citar também o trabalho de Silva e Sousa (2014), em que os autores buscaram propiciar condições à evolução conceitual de um grupo de alunos do ensino médio em uma disciplina de Física, submetendo-os a situações instrucionais sobre o comportamento ondulatório da luz, preparadas na perspectiva da TCC e da Teoria da Aprendizagem Significativa [43]. Os autores perceberam que a maior parte dos alunos foi capaz de manifestar invariantes operatórios condizentes com o proposto no estudo, verificados pela análise de testes realizados ao início e no final da intervenção. Assim, esses dados consolidam princípios da TCC, sobre o processo de enriquecimento conceitual ocorrer de maneira distinta para diferentes alunos, demonstrando a necessidade de implementação de cada vez mais situações aos alunos.

Outros trabalhos também enfocaram a aprendizagem de conceitos de física voltados ao ensino superior, como no caso da pesquisa de Bravo e Pesa (2016), que teve como objetivo o estudo do desenvolvimento cognitivo de estudantes de licenciatura em física durante a implementação de proposta didática sobre o conteúdo de interferência e difração de luz no contexto de um laboratório de física [51]. Heidemann, Araujo e Veit (2018) tiveram como objetivo trabalhar com os estudantes situações do campo conceitual da modelagem didático-científica, a fim de defrontá-los com problemas que exigissem a reflexão e tomada de decisões na modelagem de eventos físicos e, assim, desenvolvessem concepções e competências que atribuíssem sentido a invariantes operatórios do campo conceitual trabalhado [64]. Percebe-se, em ambos os trabalhos, que os resultados apontaram uma evolução nos esquemas cognitivos dos alunos, sugerindo que os preceitos da TCC foram de grande valia para a abordagem do conteúdo e análise do desenvolvimento cognitivo dos alunos, mediante o enfrentamento de situações que permitiram a mobilização de diferentes conceitos e esquemas mentais explorados.

De modo semelhante, nas pesquisas de Sahelices e Villagrá (2013) e Ferreira e Andrés (2018), [35] e [63], respectivamente, os pesquisadores utilizaram problemas no início e no final de intervenções, a partir das quais puderam analisar se as concepções explicitadas estavam de acordo com os conceitos científicos. Uma análise das respostas iniciais e finais de estudantes de licenciatura em química a duas situações foi proposta por Sahelices e Villagrá (2013), a qual teve como foco as configurações eletrônicas e os níveis de energia de diferentes estruturas atômicas e noções de Mecânica Quântica [35]. Nessas questões foi solicitada aos alunos a interpretação de uma estrutura molecular e sua configuração eletrônica, a fim de se conhecer as relações estabelecidas por eles entre os conceitos quânticos ao interpretarem estruturas atômicas e examinarem os seus estados de energia. Pelo relato dos autores, é possível perceber que a TCC forneceu elementos significativos para o estudo dos níveis de aprendizagem dos alunos, pois permitiu analisar sua atividade diante de situações com diferentes níveis de complexidade. Nesse 
processo, o professor atuou como mediador a partir do desenvolvimento de ações pautadas em preceitos favoráveis ao processo de aprendizagem. Esta é uma condição importante na perspectiva da TCC, uma vez que o professor tem papel de mediador dos conhecimentos dentro da sala de aula e é a partir dessa mediação que irá perceber os avanços e retrocessos de seus alunos acerca de sua aprendizagem (Vergnaud, 2017b).

Quanto ao enriquecimento das representações simbólicas, destaca-se o trabalho de Serrano, Konzen e Moreira (2007), em que foram realizadas práticas experimentais associadas a simulações computacionais para alunos do $2^{\circ}$ ano do ensino médio, a fim de observar a evolução dos modelos utilizados por eles, bem como o enriquecimento das suas representações simbólicas [3]. Os resultados mostraram os benefícios das simulações computacionais nos processos de mudança representacional simbólica dos alunos visto que modificaram conceitos e teoremas-em-ação outrora tidos como verdadeiros. Desse modo, os resultados corroboram o proposto na TCC de que o enfrentamento de diferentes situações abordando o mesmo conceito - com diferentes níveis de complexidade - auxilia na reiteração de conceitos/teoremas-em-ação e sua significação em distintos contextos (Hilger, \& Oliveira, 2012).

Na pesquisa de Andrade Neto, Raupp e Moreira (2009) foi realizada uma análise da evolução histórica de conceitos e representações de compostos químicos [9]. Os autores afirmam ser relevante a análise da evolução da representação dentro da química, pois permite considerar como a "noção-conceito de composto químico evoluiu", demonstrando que as novas representações tornam-se mais eficazes para a resolução de situações de maior complexidade, permitindo o desenvolvimento de invariantes operatórios mais otimizados. Essa ideia vai ao encontro do que se pretende a partir da TCC, porquanto o enriquecimento no repertório de invariantes operatórios favorece as representações simbólicas utilizadas para representá-los e tornar o conceito significativo (Moreira, 2002).

Outra estratégia com frequência significativa foi a detecção dos esquemas de ação relativos à aprendizagem de conceitos, cujo tipo de proposta foi observado no trabalho Pantoja, Moreira e Herscovitz (2014). Neste foram utilizadas situações-problema para conhecer operações implícitas do pensamento - esquemas - de cinco estudantes de graduação em Física em uma disciplina de Mecânica Quântica [42]. Nesse estudo os autores puderam observar uma mudança considerável de variáveis da estrutura cognitiva, indicando uma possível aprendizagem significativa em detrimento de uma aprendizagem repetitiva, além de reconhecerem que o conceito de probabilidade se apresentou como um possível obstáculo epistemológico. Puderam, ainda, esclarecer que o conhecimento prévio, se levado em consideração no processo educacional, tem um papel crucial na aquisição e retenção de novos conhecimentos para a resolução de problemas, fortalecendo a ideia também defendida pela TCC de que as concepções prévias dos alunos são os subsídios cognitivos de maior relevância a serem considerados pelo professor no processo de ensino-aprendizagem (Alegro, 2008).

De modo análogo, Jaime e Escudero (2011) aplicaram situações experimentais em 
um curso de engenharia cuja resolução requeria dos estudantes diferentes esquemas de ação para a sua resolução [22]. Os autores procuraram avaliar o processo de construção de conceitos em diferentes momentos de aprendizagem. Com efeito, o desenvolvimento de novos esquemas possibilita ao aluno o enfrentamento de situações com níveis mais complexos (Rocha, \& Basso, 2017). Assim, os resultados desta pesquisa indicam o potencial da TCC em fundamentar a interpretação sobre a construção do significado de conceitos outrora isolados e posteriormente integrados em estruturas mais abrangentes, e direcionar a elaboração de propostas didáticas com vistas à obtenção da aprendizagem significativa.

Vale citar, ainda, a pesquisa de Bueno Filho, Fernandez e Marzorati (2007), na qual são apresentados resultados da utilização de situações-problema na identificação dos esquemas de ação concernentes à representação estrutural utilizados por alunos de graduação em farmácia, bioquímica, engenharia e química, dentro do campo conceitual da estereoquímica [1]. De acordo com os autores, nos esquemas de ação identificados não foram contemplados conceitos importantes relacionados ao campo conceitual em estudo, os quais poderiam ter facilitado as interpretações dos estudantes a respeito das situações propostas. Esses dados consolidam a ideia advinda da TCC que o domínio de um campo conceitual requer a compreensão dos conceitos a ele relacionados. Este aspecto influencia a efetiva aprendizagem desse conteúdo e, consequentemente, a resolução de situações (Cedran, \& Kiouranis, 2019).

Silva, Nascimento, Cunha e Bueno Filho (2018) tiveram por objetivo identificar, sob a ótica da TCC, os fatores cognitivos envolvidos na solução de tarefas que envolvem a interface entre campos conceituais da cinética química de alunos de graduação [66]. Os resultados mostraram que os alunos tiveram a oportunidade de estabelecer relações entre diferentes conceitos durante a realização da atividade proposta, embora tenham apresentado dificuldades para tal. Este fato coloca em destaque a importância da contínua mediação do professor no momento da aprendizagem e na administração dos conceitos. A aprendizagem de campos conceituais, segundo a TCC, demanda tempo e o enfrentamento de situações que permitam aos estudantes enriquecer os seus repertórios de esquemas de ação. Para isso, a atuação do professor na organização didática e na escolha de situações é imprescindível.

A pesquisa de Machado e Braga (2018) foi voltada para o ensino médio, na qual investigaram a conceituação de modelagem em duas situações sobre partícula dinâmica, movimento do pêndulo e movimento horizontal, visando reconhecer sinais de abstração e idealização em seus processos de raciocínio, levando em conta as vertentes epistemológica e cognitiva [65]. Os pesquisadores relataram a relevância da pesquisa em permitir a percepção de como os alunos entendem a relação entre objetos reais e teorias e construções científicas.

Pesquisas voltadas à análise dos avanços e obstáculos na aprendizagem de conceitos científicos também se sobressaíram entre as demais pesquisas analisadas. Isto porque a TCC, de fato, permite analisar e acompanhar esse processo, tal como foi observado na 
pesquisa de Grings, Sahelices e Moreira (2008a), em que os autores buscaram investigar os possíveis avanços e retrocessos na aprendizagem de conceitos da Termodinâmica entrevistando quatro estudantes do ensino médio/técnico dos cursos de Eletrotécnica, Mecânica, Eletrônica e Química [5]. Inicialmente foram requeridas dos alunos respostas escritas e, posteriormente, explicações sobre como chegaram à resolução das questões. Nesse sentido, no trabalho ficou evidenciado, a partir das explicações dos alunos, que o conhecimento implícito tem função principal no domínio de situações e, somente por meio do processo de explicitação desse conhecimento, o professor pode auxiliar o aluno a progredir em um campo conceitual.

De maneira semelhante, Bolfe e Barlette (2009) buscaram identificar dificuldades de alunos do ensino médio na aprendizagem de conceitos de Física Térmica, especificamente relacionados aos fenômenos de dilatação e contração térmica, explorados em três situações [10]. A investigação dos possíveis invariantes operatórios revelou obstáculos conceituais à aprendizagem de novos conceitos científicos. Nessa perspectiva, destacam-se também os trabalhos [57] e [62], nos quais buscou-se analisar os obstáculos e avanços no processo de conceituação em Física. Tais pesquisas ressaltam a importância da identificação dos conhecimentos-em-ação dos estudantes, os quais podem se tornar obstáculos à obtenção de conceitos científicos por serem implícitos e não terem sua explicitação habitualmente incentivada (Grings, Caballero, \& Moreira, 2006).

O trabalho desenvolvido por Henríquez, Gallardo e Pinto (2013) traz resultados de uma análise descritiva da aprendizagem de estudantes de engenharia a respeito dos conceitos de força e energia [33]. Os resultados mostraram progresso na conceituação e compreensão de significados científicos, os quais puderam ser observados por terem sido analisados no início e ao final do processo, permitindo um acompanhamento do progresso dos estudantes para a aprendizagem e domínio do campo conceitual.

Citamos, ainda, o artigo de Brandão, Araujo e Veit (2014), no qual são apresentadas as concepções de modelo científico, os avanços e as dificuldades de uma estudante de mestrado em Ensino de Física no processo de conceitualização [40]. Um aspecto relevante apontado neste trabalho é a colocação de que os estudantes fazem exemplificações por meio de um conjunto de situações em que se emprega dado conhecimento, no entanto, não são de fato capazes de aplicá-lo, de explicar verbalmente os esquemas utilizados para chegar ao resultado e exprimir as concepções confrontadas para a resolução. Sobre esse aspecto, Greca e Moreira (2003) explicam que a resolução de situações e a aprendizagem conceitual estão estreitamente relacionadas. Por exemplo, o aluno pode até memorizar o princípio de inércia, entretanto, pode não saber como aplicá-lo. Segundo os autores, para que o aluno passe a compreender um conceito é necessário que enfrente diferentes situações que permitam reconhecê-lo de modo que atribua significado a ele. Logo, é por meio das situações que ele aprenderá como aplicar o conceito e, em seguida, explicitálo, permitindo ao professor inferir se houve uma aprendizagem significativa com a incorporação desse princípio à sua estrutura cognitiva. 
Outra estratégia observada foi a implementação de situações-problema para a introdução de conceitos científicos relativos à temperatura, como verificado no estudo de Grings, Sahelices e Moreira (2008b). A resolução da situação foi conduzida por discussões entre alunos de ensino médio, os quais acionaram diferentes esquemas para resolver as situações, favorecendo seu desenvolvimento cognitivo [6]. A relevância dessa pesquisa se fundamenta na evidência de que a desestabilização gerada pela resolução de problemas contribui com o desenvolvimento de esquemas, permitindo ao professor conduzir os estudantes na aquisição dos conceitos necessários à aprendizagem de um conteúdo (Vergnaud, 2017a).

É também digno de nota o trabalho de Rocha, Herscovitz e Moreira (2010), o qual envolveu a realização de um minicurso para licenciados e licenciandos em Física, com o propósito de avaliar os efeitos de um ensino introdutório ou complementar de mecânica quântica [19]. Segundo os autores, por se tratar de um curso de curta duração, não houve a intenção de avaliar a aprendizagem dos participantes da pesquisa, mas seu envolvimento com os conteúdos trabalhados. Nesse sentido, a pesquisa se fundamentou na investigação sobre a abordagem dos conteúdos por meio de problemas, com base na TCC. Com a mesma natureza, Schittler e Moreira (2016) investigaram a eficiência de uma proposta de introdução de conceitos fundamentais de Física Moderna e Contemporânea no primeiro ano do ensino médio por meio do modelo de Unidade de Ensino Potencialmente Significativa (UEPS) baseada, entre outras teorias, na TCC [52]. Os resultados indicaram que a utilização da UEPS, aliada aos princípios de diferentes teorias, como a noção de situação-problema da TCC, mostrou-se promissora para a obtenção da aprendizagem significativa dos estudantes, visto que apresentaram um aproveitamento consideravelmente positivo na resolução das situações propostas.

Nesta categoria foi também identificado o trabalho de Moreira e Sperling (2009), em que alunos de ensino médio discutiram as qualidades inerentes a um correto mapa conceitual [15]. A situação-problema proposta nesta pesquisa se deu a partir da elaboração de mapas no início e ao final do trabalho seguida de discussões sobre as suas principais diferenças. Esse trabalho traz a ideia de que o professor, por intermédio do acompanhamento do desenvolvimento cognitivo de seus alunos, tem a possibilidade de verificar as concepções prévias, os níveis cognitivos e/ou ainda os conceitos-emação e teoremas-em-ação inerentes ao processo de aprendizagem. Por conseguinte, é a partir dessa mediação que o educador irá perceber os avanços e retrocessos de seus alunos acerca de sua aprendizagem. Em contraste com o ensino centrado no professor, a proposta de Vergnaud (2017b) está pautada na ação do aluno e suas evoluções cognitivas.

\section{Análise dos invariantes operatórios}

Dentre as pesquisas analisadas, 14 delas trataram da análise dos invariantes operatórios, nas quais foram verificadas diferentes estratégias aplicadas nas seguintes perspectivas:

a) Levantamento dos possíveis invariantes operatórios $[11 ; 25 ; 29 ; 34 ; 39 ; 54 ; 59]$; 
b) Observação da conceitualização dos alunos para a identificação dos invariantes operatórios $[13 ; 32 ; 47 ; 53]$;

c) Realização de entrevistas a fim de conhecer os invariantes operatórios do sujeito-em-situação [37; 46; 56].

Vale salientar que os invariantes operatórios têm um papel imprescindível para o desenvolvimento cognitivo dos estudantes e se constituem a parte conceitual dos esquemas, isto é, o próprio conhecimento contido neles (Moreira, Caballero, \& Vergnaud, 2010). Diante disso, os autores reconheceram em suas pesquisas a relevância que a identificação e análise dos invariantes operatórios apresentam no processo de aprendizagem, pois determinam as articulações conceituais que os estudantes realizam em situação. Nesse sentido, em alguns trabalhos o propósito foi conhecer os possíveis invariantes operatórios integrantes das representações mentais de estudantes dos níveis médio e superior $[11 ; 25 ; 29 ; 34 ; 39 ; 54 ; 59]$.

Entre eles, cabe menção a pesquisa de Parisoto, Moreira e Moro (2013), na qual foram identificados e avaliados possíveis invariantes operatórios a partir das respostas dadas a três situações-problema elaboradas com o propósito de atribuir significados aos conceitos do campo conceitual relativo à Óptica, Eletromagnetismo e Física Moderna [34]. Os autores perceberam um progresso no que diz respeito aos invariantes operatórios articulados aos conceitos, fornecendo indícios de aprendizagem significativa. Trabalhos dessa natureza apresentam relevância porque mostram caminhos para o professor avaliar tanto o aprendizado dos alunos, como sua prática de ensino, considerando-a ferramenta mediadora da aprendizagem.

O processo de conceitualização, de modo mais detalhado, foi observado em outras pesquisas nas quais buscou-se promover meios em favorecer o processo de explicitação dos conhecimentos pelos alunos, visto que a boa parte dos conhecimentosem-ação (invariantes operatórios) não são explícitos, tampouco de forma consciente (Vergnaud, 2013). Assim, cabe ao professor promover meios para tanto. Partindo desse pressuposto, nos trabalhos [13], [32] e [47] procurou-se conhecer, por intermédio da conceitualização, estes elementos implícitos, propondo situações para que pudessem ser explicitados de forma progressiva e se tornarem verdadeiros conceitos e teoremas. Segundo Vergnaud (2017a), os conceitos e teoremas-em-ação não são inteiramente um conceito, nem um teorema-em-ação é um teorema, isso ocorre por meio da explicitação das concepções dos alunos.

Como exemplo, Carvalho Júnior, Aguiar Júnior e Bruno (2013) analisaram o processo de conceitualização em Física em um diálogo entre um professor, estudantes e pesquisador [32]. Os autores avaliaram a evolução dos invariantes operatórios usados pelos estudantes na conexão entre os campos conceituais da Mecânica Clássica e da Relatividade Restrita. Nesse diálogo, os autores identificaram teoremas-em-ação tanto inadequados, como próximos aos aceitos cientificamente. Tal proposta mostra a relevância em conhecer os conceitos-em-ação e teoremas-em-ação para verificar o 
nível de assimilação de dado campo conceitual e conhecer esses "pseudoconceitos", geralmente implícitos. Isto proporciona ao professor discuti-los e direcioná-los a se tornarem pertinentes e verdadeiros conceitos e teoremas científicos. Esses resultados reforçam a pertinência de sua explicitação e discussão, além da intervenção do professor (Vergnaud, 1996).

Nesse sentido, a realização de entrevistas associadas à resolução de problemas mostra-se promissora em auxiliar o processo de reconhecimento dos conhecimentosem-ação dos alunos, como observado nos trabalhos [37], [46] e [56], nos quais o propósito foi conhecer os invariantes operatórios (conceitos e teoremas-em-ação) mobilizados em situação.

Na pesquisa de Souza (2013), a título de exemplo, esses conhecimentos foram explicitados durante os afazeres diários de um trabalhador de cultivo de arroz durante a construção do Manzuá, um objeto usado para a pesca [37]. Através de análise e simultânea entrevista, constatou-se que o trabalhador fez uso de conceitos físicos subjacentes sobre rigidez de materiais, densidade, força e troca de calor sem ter "consciência dessa utilização". Nesse trabalho, o autor explicou que a análise dos invariantes operatórios elucidados pelo sujeito entrevistado mostrou-se uma proposta a ser levada para a sala de aula, visto que possibilita o estabelecimento de relações mentais aos modelos científicos.

\section{Uso das tecnologias na promoção da aprendizagem de conceitos científicos sob a ótica da TCC}

O uso de tecnologia como auxílio à aprendizagem de conceitos científicos sob a ótica da TCC também foi foco de diferentes pesquisas, as quais aliaram as potencialidades da teoria ao uso de softwares para facilitar o ensino de ciências $[16 ; 20 ; 27 ; 28 ; 48]$. Reitera-se que o uso de tal ferramenta em sala de aula pode facilitar a compreensão de diversos conceitos, à medida que promove a motivação dos alunos a participarem das atividades.

Com relação à superação de dificuldades na compreensão de conceitos, no trabalho de Raupp, Serrano e Moreira (2009) ficou verificado que, após a implementação de softwares de construção de modelos químicos com alunos de cursos de graduação em Engenharia Química, Química Industrial e licenciatura em Química, estes foram capazes de resolver situações elaboradas na perspectiva da TCC, indicando um avanço com relação à aprendizagem do conteúdo trabalhado [16]. Para a realização da pesquisa, os autores organizaram as atividades em três etapas. Na etapa inicial foi aplicado um questionário (pré-teste) antes de os alunos terem contato com as ferramentas, com três questões sobre isomeria geométrica, cujas respostas deveriam ser apresentadas por escrito. Na etapa seguinte foram aplicadas aulas sobre como manusear a ferramenta Chemsketch para a criação de estruturas moleculares. Por fim, foi aplicado um segundo teste (pós-teste), sem o uso do software, para o qual os alunos deveriam representar pares de isômeros. O estudo apontou uma evolução representacional nas respostas de alguns alunos, corroborando o proposto por Vergnaud (2009) sobre as representações 
simbólicas serem imprescindíveis ao aluno na solução de diferentes problemas.

Nesse segmento, uma técnica de análise gestual de estudantes foi utilizada na pesquisa de Engel e Serrano (2011) a fim de analisar a relação entre a exposição de gestos descritivos e o desenvolvimento conceitual dos estudantes quando submetidos a simulações computacionais abordando o conteúdo de Física Mecânica, especialmente o conceito de Conservação de Energia [20]. A partir do uso de um software como auxílio na elaboração de problemas, os autores concluíram que as simulações computacionais são ferramentas que podem favorecer o aprendizado de conceitos físicos, por fornecerem aos alunos a oportunidade de assimilação de representações e invariantes operatórios, imprescindíveis à aprendizagem de conceitos.

Dentro dessa categoria, foram também identificados trabalhos com o uso de tecnologia voltada a estudantes com deficiência visual. Viveiros e Camargo (2011b, 2011c) investigaram o sistema semiótico elaborado por estudantes ao buscarem resolver problemas de Física envolvendo a montagem de protótipos experimentais utilizando-se uma unidade robótica, com a finalidade de conhecer os esquemas, conceitos e teoremasem-ação, bem como as representações desenvolvidas pelos estudantes [27; 28]. Com base nas ponderações dos autores, as Tecnologias Assistivas por si mesmas não são suficientes para fins didáticos, mas podem ser quando associadas a uma base teórica como a TCC, especialmente a noção de campos conceituais, conceitos e teoremas-em-ação. Assim, os autores ressaltam que a TCC, como uma teoria com base semiótica, atrelada aos princípios teóricos da Biônica, se constitui uma interessante estratégia para o ensino de Física por considerar três momentos imprescindíveis no ensino, que são a "percepção (das situações didáticas), a compreensão (momento do processo de conceitualização) e a consequente representação" [28]. Tal constatação se assemelha ao que foi observado na pesquisa de Fioreze, Barone, Basso e Isaia (2013), na qual detectou-se que a TCC se apresentou como um importante referencial para a análise de resultados obtidos a partir do uso de recursos digitais, permitindo analisar as construções conceituais dos estudantes, bem como a evolução dos modelos explicativos esboçados por eles.

\section{Formação de professores e as contribuições da TCC}

Verificamos, ainda, trabalhos que buscaram relacionar o processo de formação inicial e continuada de professores com fundamentos da TCC, demonstrando a relevância em discutir a prática docente tendo em vista uma formação mais reflexiva [2; $8 ; 14 ; 17 ; 23 ; 38 ; 41 ; 44 ; 49 ; 50 ; 58]$. Dentre os tópicos explorados nas pesquisas destacamse aqueles que envolvem a análise da evolução da aprendizagem de professores, como nas pesquisas [23], [38] e [49], em que os autores buscaram conhecer a evolução da aprendizagem de conceitos relacionados à prática docente, segundo a TCC.

Tauceda, Del Pino, Nunes e Witt (2015) sugeriram a um professor de química de ensino médio, em formação continuada, reflexões a partir de situações-problema tendo como eixo norteador a "alfabetização científica" para o desenvolvimento de práticas de ensino que proporcionem aos estudantes uma aprendizagem baseada na investigação 
científica [49]. O conceito de "epistemologia" de licenciandos em Ciências da Natureza, divididos em dois grupos, um com enfoque no ensino tradicional e outro nos preceitos da TCC, foi explorado no trabalho de Tauceda, Del Pino e Nunes (2013) [38]. Matos e Martins (2011) procuraram compreender as premissas do "ensino por investigação" na perspectiva da TCC e verificar uma possível evolução conceitual de uma professora em formação continuada sobre essa modalidade de ensino [23].

Vale destacar que nesses estudos tais conceitos foram assim classificados a partir da noção de campos conceituais proposta na TCC, em que o domínio desses conceitos implica na aprendizagem e mobilização de diferentes outros conceitos. Nas pesquisas relatadas, são trabalhados conceitos relacionados à prática educativa, em que a aprendizagem dos mesmos possibilita o desenvolvimento de práticas de ensino com significados epistemológicos diferentes aos que são propostos no ensino tradicional [49]; a compreensão de como ocorre a construção do conhecimento científico [38], bem como a aprendizagem e aplicação de conceitos como problematização, autonomia, evidências, argumentação [23].

Além desses conceitos, no trabalho de Acioly-Régnier e Monin (2009) foram propostas situações em que foram explorados conceitos da psicologia e sociologia na formação inicial de professores durante o estágio curricular, baseadas na didática profissional e nos princípios cognitivistas da TCC [8]. Ao realizarem uma análise conceitual mais criteriosa, as autoras perceberam que um dos professores utilizou esquemas pouco abrangentes na ministração do conteúdo, isto é, esquemas insuficientes para a implementação de situações mais diversificadas, que exigissem de seus alunos esquemas mais estruturados, demonstrando limitações existentes em seu próprio nível de conceitualização. Dessa forma, os conceitos trabalhados pelo professor em sala de aula ficaram restritos a uma única situação. No entanto, para outro conceito, o mesmo professor demonstrou domínio e articulação de aspectos relativos à psicologia. Pesquisas nessa linha apresentam-se pertinentes para a melhoria da concepção de práticas pedagógicas a fim de favorecer o universo de estudos referentes à formação de professores.

Ainda foi possível verificar nesta categoria pesquisas pautadas em discussões sobre a relação entre a teoria aprendida durante a graduação e a prática educacional, como na pesquisa de Tauceda e Del Pino (2014), que aborda uma discussão sobre fundamentos da TCC com professores em um contexto do Programa Institucional de Bolsas de Iniciação à Docência do Instituto Federal de Educação, Ciência e Tecnologia do Rio Grande do Sul (PIBID/IFRS) [44]. Com foco na narrativa do professor, a discussões ocorreram em torno do ensino centrado no aluno e no lema pedagógico "aprender a aprender". Em outro trabalho, Tauceda e Del Pino (2017) propuseram discussões sobre a formação inicial e a elaboração de protocolos para aulas práticas, com enfoque teórico na perspectiva da reflexão-ação de Schön, e dos campos conceituais de Vergnaud [58].

No trabalho de Lima e Teixeira (2007) também foram discutidas as ações pedagógicas do ponto de vista de sua complexidade, apontando os resultados preliminares 
e principais obstáculos de pesquisas que investigam o desenvolvimento e realização de atividades desenvolvidas em um centro de ensino experimental [2]. Os sujeitos dessa pesquisa foram professores de física, química, biologia e matemática e uma coordenadora pedagógica. Com os resultados preliminares obtidos, além do reconhecimento de possíveis obstáculos à atividade interdisciplinar, os autores perceberam uma evolução no que diz respeito à adoção dessa prática nas atividades realizadas no centro.

Uma outra vertente abordada foi a análise da TCC como embasamento teórico na organização de ações na formação inicial de professores, como observada na pesquisa de Castaño, Andrés e Villagrá (2014), em que um grupo de licenciandos foi instruído acerca dos preceitos da TCC e sua possibilidade de aplicação em sala de aula [41]. Os resultados alcançados mostraram que os benefícios da TCC na mediação didática, bem como na organização e ensino de conteúdos de ciências e matemática.

Identificamos também pesquisas envolvendo a utilização de situações-problema com professores em formação [14; 17]. Krey e Moreira (2009) delinearam situaçõesproblema para a aprendizagem de conceitos de Física de Partículas em uma intervenção didática na formação inicial de professores de Física para o ensino médio, cujos resultados sugeriram que a metodologia promoveu a aprendizagem significativa dos conteúdos trabalhados - evidenciada na clareza e coerência conceitual das resoluções, indicando domínio dos conceitos explorados - e motivou os futuros professores a explorarem esses conceitos com seus alunos [14].

Na mesma vertente, a pesquisa de Brandão, Araujo e Veit (2010) traz um estudo das principais concepções e obstáculos demonstrados por oito professores do ensino médio durante a resolução de situações trazendo aspectos conceituais da estrutura conceitual de referência proposta (ECR) da modelagem científica em Física [17]. Os resultados indicam que os professores tiveram dificuldades em distinguir teorias com modelos científicos, proposições de lei, equações, analogias, situações, entre outros aspectos. Esses resultados mostraram-se relevantes em virtude do que é defendido pela TCC, a qual explica que a compreensão e as barreiras apresentadas pelos professores no processo de conceitualização estão relacionadas à aquisição de novos conhecimentos para resolver diferentes situações de determinado conteúdo e à possibilidade de estarem atuando como obstáculos epistemológicos na elaboração de conceitos científicos. Portanto, faz-se necessária a identificação da compreensão e dificuldades de professores atuantes com relação aos conteúdos, bem como de suas explicitações.

Além disso, Andrade e Acioly-Régnier (2016) estudaram os impactos do uso de um Dispositivo Pedagógico Tecnológico Híbrido (DPTH) na formação inicial de professores, o qual foi desenvolvido utilizando-se um suporte de criação de histórias em quadrinhos (HQ) on-line na resolução de problemas. Foram analisados textos escritos pelos licenciandos sobre a simulação de conflitos e soluções de situações vivenciadas na sala de aula [50]. Segundo constatado pelos autores, os resultados mostraram que os licenciandos se apropriaram de conceitos e ações semelhantes nas resoluções dos conflitos pedagógicos evocados. 


\section{Conclusões e implicações}

A seleção realizada apontou significativa quantidade de trabalhos voltados à TCC no ensino de ciências no período pesquisado. Os dados quantitativos sinalizam direcionamentos importantes a serem dados com relação a estudos futuros sobre as contribuições da teoria para o ensino de ciências, como o desenvolvimento de trabalhos concernentes à aprendizagem de estudantes em níveis mais elementares, tal qual no ensino fundamental, e indicam a necessidade de melhor conhecer o processo de conceitualização relativo a concepções fundamentais da química e da biologia, imprescindíveis ao ensino médio e superior.

A análise dos trabalhos selecionados mostrou diferentes linhas de estudos pautadas na TCC, as quais apontaram as potencialidades desta teoria para o ensino de ciências a partir de estudos teóricos e empíricos. Nas pesquisas teóricas foi possível vislumbrar aspectos fundamentais da TCC, demonstrando sua pertinência ao processo de ensino e aprendizagem de ciências por se basear no estudo da construção de conhecimentos científicos e auxiliar professores na compreensão dos processos e práticas de ensino. A partir das investigações empíricas foi possível observar exemplos de pesquisas em que foram investigadas as contribuições da teoria, tanto na busca de compreensão dos mecanismos de aprendizagem, como na identificação e análise de invariantes operatórios, quanto nas propostas de intervenção, nas quais identificamos o emprego de métodos e recursos elaborados segundo a teoria.

Nesses trabalhos contatamos, portanto, os benefícios do uso de situaçõesproblema para o processo de conceitualização, as quais, aliadas a estratégias bem pensadas, auxiliam o aluno no seu desenvolvimento cognitivo. Os estudos que apresentaram a análise dos invariantes operatórios revelaram a sua importância nas articulações conceituais que os estudantes realizam em uma situação. As pesquisas realizadas em associação à tecnologia demonstraram ser este um recurso valioso na efetivação de propostas didáticas baseadas na TCC, por facilitarem a aprendizagem de conceitos científicos e estimularem a participação dos sujeitos.

Foram identificadas, também, pesquisas voltadas à formação de professores com vistas à formação reflexiva, promovendo debates e reuniões com professores de ciências em formação inicial e continuada. Contudo, evidenciamos que estudos voltados à preparação de professores em formação inicial e continuada para a compreensão dos princípios defendidos na teoria e sua aplicação em sala de aula foram pouco explorados nas pesquisas analisadas nesta revisão. Logo, entendemos a relevância em tornar explícitos aos professores os aspectos da teoria, de modo que possam avaliar tanto o modo como compreendem determinado conceito, quanto as estratégias que serão acionadas para ensiná-lo. Investigações desta natureza permitiriam analisar de que forma os elementos da teoria auxiliam os professores em seu planejamento didático e se concretizam em estratégias que favoreçam a construção de conhecimentos.

Embora se reconheça que os resultados obtidos nessa busca não representem a totalidade das pesquisas acerca dessa temática, visto que muitos pesquisadores 
apresentam seus estudos em outros eventos da área de ensino e educação, como também em outros periódicos nacionais e internacionais não contemplados nesta revisão, com a análise realizada foi possível conhecer as distintas propostas de implementação da TCC na área de ensino de ciências. Nesse sentido, ressaltamos a pertinência de pesquisas que abordem esta temática pelas diferentes contribuições da teoria sinalizadas a pesquisadores da área. Os exemplos de aplicação da teoria retratados nas pesquisas, bem como as constatações delas alcançadas, são igualmente relevantes aos professores, por apresentarem caminhos para uma organização didática que permita compreensão e acompanhamento do processo de aprendizagem e uma reflexão sobre a prática docente, reconhecendo a importância de seu papel na mediação e suas limitações.

Portanto, o presente estudo se apresenta como considerável instrumento de busca de dados para pesquisadores que busquem enriquecer sua prática de ensino e/ou desenvolver pesquisas tendo em conta os princípios da TCC, visto que o mapeamento da produção acadêmica referente a dada temática configura significativo subsídio ao permitir um olhar panorâmico das variadas formas de entendimento a respeito do tema estudado, assim como a verificação de aspectos positivos e lacunas a serem preenchidas por novos estudos.

\section{Agradecimentos}

À CAPES, pelo auxílio financeiro.

\section{Referências}

Alegro, R. C. (2008). Conhecimento prévio e aprendizagem significativa de conceitos históricos no ensino médio. (Tese de doutorado). Universidade Estadual Paulista, Faculdade de Filosofia e Ciências, São Paulo.

Andrés, M. M., Pesa, M. A., \& Villagrá, J. A. M. (2008). Efectividad de un laboratorio guiado por el modelo de aprendizaje matlaf para el desarrollo conceptual asociado a tareas experimentales. Enseñanza de las Ciencias, 26(3), 343-358.

Bardin, L. (1977). Análise de conteúdo. Edições 70.

Cedran, D. P., \& Kiouranis, N. M. M. (2019). Teoria dos campos conceituais: visitando seus principais fundamentos e perspectivas para o ensino de ciências. ACTIO, 4(1), $63-$ 86. https://doi.org/10.3895/actio.v4n1.7709

Fioreze, L. A., Barone, D., Basso, M., \& Isaia, S. (2013). Análise da construção dos conceitos de proporcionalidade com a utilização do software geoplano virtual. Ciência \& Educação, 19(2), 267-278. http://dx.doi.org/10.1590/S1516-73132013000200003

Freire, P. (1996). Pedagogia da autonomia: saberes necessários à prática educativa. Paz e terra. 
Greca, I. M., \& Moreira, M. A. (2003). Do saber fazer ao saber dizer: Uma análise do papel da resolução de problemas na aprendizagem conceitual de Física. Ensaio Pesquisa em Educação em Ciências, 5(1), 1-16. http://dx.doi.org/10.1590/1983-21172003050106

Grings, E. T. O., Caballero, M. C., \& Moreira, M. A. (2006). Possíveis indicadores de invariantes operatórios apresentados por estudantes em conceitos da termodinâmica. Revista Brasileira de Ensino de Física, 28(4), 463-471. http://dx.doi.org/10.1590/S180611172006000400009

Grings, E. T. O., Caballero, M. C., \& Moreira, M. A. (2008). Avanços e retrocessos dos alunos no campo conceitual da Termodinâmica. Revista Electrónica de Enseñanza de Las Ciencias, 7(1), 23-46.

Hilger, T., \& Oliveira, A. (2012). O problema dos falsos teoremas-em-ação sobre a força de atrito na disciplina de física geral para graduação. Revista Brasileira de Ensino de Ciência e Tecnologia, 5(1), 54-70. http://dx.doi.org/10.3895/S1982-873X2012000100004

Linde, K., \& Willich, S. N. (2003). How objective are systematic reviews? Differences between reviews on complementary medicine. Journal of the royal society of medicine, 96(1), 17-22. https://doi.org/10.1258/jrsm.96.1.17

Moreira, M. A. (2002). A teoria dos campos conceituais de Vergnaud, o ensino de ciências e a pesquisa nesta área. Investigações em ensino de ciências, 7(1), 7-29.

Moreira, M. A. (2009). Subsídios teóricos para o professor pesquisador em ensino de ciências: A Teoria da Aprendizagem Significativa. http://moreira.if.ufrgs.br/Subsidios5. pdf.

Moreira, M. A., Caballero, C., \& Vergnaud, G. (2010). La Teoría de los Campos Conceptuales y la Enseñanza Aprendizaje de las Ciencias. UBU, 13(1).

Rocha, K. C., \& Basso, M. V. A. (2017). Programação em Scratch na Sala de Aula: investigações sobre a construção do conceito de ângulo. RENOTE, 15(1), 725-734. http://dx.doi.org/10.5753/cbie.wie.2019.725

Scheffler, G. L., \& Del Pino, J. C. (2013). A teoria dos campos conceituais de Vergnaud e o ensino da radioatividade. Experiências em Ensino de Ciências, 8(1), 29-46.

Souza, C. M. S. G., \& Fávero, M. H. (2002). Análise de uma situação de resolução de problemas de física, em situação de interlocução entre um especialista e um novato, à luz da teoria dos campos conceituais de Vergnaud. Investigações em Ensino de Ciências, $7(1), 55-75$.

Vasconcelos, C., Praia, J. F., \& Almeida, L. S. (2003). Teorias de aprendizagem e o ensino/aprendizagem das ciências: Da instrução à aprendizagem. Psicologia Escolar e Educacional, 7(1), 1-19. http://dx.doi.org/10.1590/S1413-85572003000100002

Vergnaud, G., Rogalski, J., \& Artique, M. (1989). Paris, France. https://files.eric.ed.gov/ fulltext/ED411141.pdf 
Vergnaud, G. (1996). Algunas ideas fundamentales de Piaget en torno a la didáctica. Perspectivas, 26(10), 195-207.

Vergnaud, G. (2009). The theory of conceptual fields. Human development, 52(2), 83-94. https://doi.org/10.1159/000202727

Vergnaud, G. (2013). Pourquoi la théorie des champs conceptuels? Infancia y Aprendizaje, 36(2),131-161. https://doi.org/10.1174/021037013806196283

Vergnaud G. (2017a). O que é aprender? Iceberg da conceitualização. GEEMPA.

Vergnaud, G. (2017b). Piaget e Vygotsky em Gérard Vergnaud Teoria dos Campos Conceituais. GEEMPA.

Viecheneski, J. P., Lorenzetti, L., \& Carletto, M. R. (2012). Desafios e práticas para o ensino de ciências e alfabetização científica nos anos iniciais do ensino fundamental. Atos de pesquisa em educação, 7(3), 853-876. http://dx.doi.org/10.7867/18090354.2012v7n3p853-876

\author{
Kariny Mery Araujo Cunha \\ https://orcid.org/0000-0003-1975-880X \\ Universidade Federal do Piauí \\ Programa de Pós-Graduação em Química \\ Teresina, Piauí, Brasil \\ karinymery@gmail.com \\ Luciana Nobre de Abreu Ferreira \\ https://orcid.org/0000-0003-3505-9523 \\ Universidade Federal do Piauí \\ Curso de Licenciatura em Ciências da Natureza \\ Teresina, Piauí, Brasil \\ luciananobre@ufpi.edu.br
}

Submetido em $\mathbf{2 5}$ de fevereiro de $\mathbf{2 0 2 0}$

Aceito em $\mathbf{2 6}$ de maio de 2020

Publicado em 06 de julho de 2020 